\title{
Curcumin Pretreatment Induces Nrf 2 and an Antioxidant Response and Prevents Hemin-Induced Toxicity in Primary Cultures of Cerebellar Granule Neurons of Rats
}

\author{
Susana González-Reyes, ${ }^{1}$ Silvia Guzmán-Beltrán, ${ }^{2}$ \\ Omar Noel Medina-Campos, ${ }^{1}$ and José Pedraza-Chaverri ${ }^{1}$ \\ ${ }^{1}$ Departamento de Biología, Facultad de Química, Edificio F, Segundo Piso, Laboratorio 209, \\ Universidad Nacional Autónoma de México (UNAM), Ciudad Universitaria, 04510 México, DF, Mexico \\ ${ }^{2}$ Instituto Nacional de Enfermedades Respiratorias "Ismael Cosío Villegas," 14080 Tlalpan, México, DF, Mexico \\ Correspondence should be addressed to José Pedraza-Chaverri; pedraza@unam.mx
}

Received 12 October 2013; Accepted 15 November 2013

Academic Editor: Verónica Pérez de la Cruz

Copyright @ 2013 Susana González-Reyes et al. This is an open access article distributed under the Creative Commons Attribution License, which permits unrestricted use, distribution, and reproduction in any medium, provided the original work is properly cited.

Curcumin is a bifunctional antioxidant derived from Curcuma longa. This study identifies curcumin as a neuroprotectant against hemin-induced damage in primary cultures of cerebellar granule neurons (CGNs) of rats. Hemin, the oxidized form of heme, is a highly reactive compound that induces cellular injury. Pretreatment of CGNs with 5-30 $\mu \mathrm{M}$ curcumin effectively increased by $2.3-$ 4.9 fold heme oxygenase-1 (HO-1) expression and by 5.6-14.3-fold glutathione (GSH) levels. Moreover, $15 \mu \mathrm{M}$ curcumin attenuated by $55 \%$ the increase in reactive oxygen species (ROS) production, by $94 \%$ the reduction of GSH/glutathione disulfide (GSSG) ratio, and by $49 \%$ the cell death induced by hemin. The inhibition of heme oxygenase system or GSH synthesis with tin mesoporphyrin and buthionine sulfoximine, respectively, suppressed the protective effect of curcumin against hemin-induced toxicity. These data strongly suggest that HO-1 and GSH play a major role in the protective effect of curcumin. Furthermore, it was found that $24 \mathrm{~h}$ of incubation with curcumin increases by 1.4-, 2.3-, and 5.2-fold the activity of glutathione reductase, glutathione S-transferase and superoxide dismutase, respectively. Additionally, it was found that curcumin was capable of inducing nuclear factor (erythroidderived 2)-like 2 (Nrf2) translocation into the nucleus. These data suggest that the pretreatment with curcumin induces Nrf2 and an antioxidant response that may play an important role in the protective effect of this antioxidant against hemin-induced neuronal death.

\section{Introduction}

The use of natural products has been a general approach for regulating antioxidant homeostasis in cells. Curcumin is a yellow polyphenol compound found in turmeric, derived from Curcuma longa Linn. [1]. Curcumin has shown to be an effective anticarcinogenic, antiviral, antioxidant [2-5], and anti-inflammatory substance in human, cell cultures and animal models $[6,7]$.

Curcumin acts as a direct and an indirect antioxidant since it scavenges reactive oxygen and nitrogen species $[8,9]$ and induces cytoprotective enzymes such as glutathione-Stransferase (GST), $\gamma$-glutamyl cysteine ligase ( $\gamma$-GCL), heme oxygenase-1 (HO-1), among others $[10,11]$. Curcumin is able to scavenge hydrogen peroxide, peroxyl radicals, superoxide anion, hydroxyl radicals, singlet oxygen, nitric oxide, and peroxynitrite anion [8]. It has been shown that curcumin induces endogenous antioxidant defense mechanisms by modulating transcription factors such as nuclear factor (erythroidderived 2)-like 2 (Nrf2) [4], activator protein-1 (AP-1), and nuclear factor kappa $\mathrm{B}(\mathrm{NF} \kappa \mathrm{B})$ [12]. Nrf2 is maintained primarily in the cytoplasm, where it remains bound to the BTBKelch-like ECH-associated protein 1 (Keap1 or KLHL19); Keapl acts as a receptor of electrophilic compounds and promotes Nrf2 ubiquitination for subsequent degradation by $26 S$ proteasome complex $[13,14]$. Modification of Keap 1 by oxidation or alkylation (e.g., curcumin interaction) releases 
Nrf2 and then Nrf2 translocates into the nucleus where it binds as a heterodimer to the antioxidant responsive element in DNA to initiate target gene expression. Nrf2-regulated genes can be classified into phase II xenobiotic-metabolizing antioxidants enzymes, molecular chaperones, DNA repair enzymes, and anti-inflammatory response proteins [15]. These proteins reduce electrophiles and free radicals to less toxic intermediates whilst increasing the ability of the cell to repair any subsequent damage $[1,10,15,16]$. In this regard, curcumin is able to induce protection and activate Nrf2dependent protective responses in cell lines or animal models exposed to oxidative conditions $[17,18]$.

Hemin, a degradation product of hemoglobin, is released by the lysis of red blood cells in hemorrhagic strokes [19, 20]. This molecule is degraded by the isoforms of the heme oxygenase (HO) system: the inducible isoform HO-1 and the constitutive heme oxygenase 2 (HO-2). The $\mathrm{HO}$ reaction decreases levels of prooxidant heme, increases the antioxidant biliverdin, and releases antiapoptotic carbon monoxide (CO) [20]. In addition, hemin is a highly reactive compound and a dangerous molecule related to a wide variety of oxidative mechanisms, most of which include enzymatic reactions [21]. Furthermore, it is also known that hemin itself is redoxactive and is able to react with peroxides to produce cytotoxic free radicals and oxidative stress. Moreover, hemin is lipophilic and intercalates into the plasma membrane, which may induce lipid peroxidation, as well as interference with membrane fluidity and function [20]. Also, hemin rapidly depletes astrocytic GSH via a peroxynitrite-dependent mechanism before the induction of cell death [22]. It has been demonstrated that hemin is quickly accumulated and slowly degraded by $\mathrm{HO}$, which causes damage primarily, in rat astrocytes and neurons $[23,24]$. In addition, hemin irondependent injury is not fully established because iron chelators (phenanthroline and deferoxamine) were not able to alleviate the damaging effects of hemin [22, 23]. Moreover, in astrocytes it was found that antioxidants such as trolox or $\mathrm{N}$-acetyl cysteine were not capable of reducing the damage induced by hemin [23]. Therefore, new strategies are essential to counteract the damage induced by hemin. These strategies may involve the improving of the antioxidant potential of brain cells by stimulating HO-1 expression to enhance hemin degradation (to avoid its participation in redox reactions) and the increasing of nonenzymatic antioxidants such as GSH and another cytoprotective enzymes. In this context, curcumin has a plethora of biological effects such as iron chelating, direct, and indirect antioxidant and hormetin (inductor of mild stress) on animal and cell models [25-28].

Taking into account the antioxidant properties of curcumin and the oxidant-mechanisms involved in the toxicity induced by heme groups, the hypothesis was made that curcumin may be able to attenuate the damage induced by hemin in primary cultures of cerebellar granule neurons (CGNs) of rats. It was found that the pretreatment of CGNs neurons effectively prevented hemin-induced oxidative damage. This protective effect was associated with a significant nuclear translocation of Nrf2 and an increase in enzymatic and nonenzymatic antioxidants.

\section{Experimental Procedures}

2.1. Reagents. Curcumin (1,7-bis(4-hydroxy-3-methoxyphenyl)-1,6-heptadiene-3,5-dione, high purity $\geq 98.5 \%$, catalogue no. ALX-350-028-M050, lot no. L12586) was obtained from Enzo Life Sciences, Inc. (Ann Arbor, MI, USA). Basal Medium Eagle (BME), trypsin, deoxyribonuclease type I (DNAse I), cytosine arabinoside, glutamine, glucose, gentamicin, hemin (catalogue no. H5533, lot no. 110K1094), 3-[4,5-dimethylthiazol-|2-yl)]-2,5-diphenyl-tetrazolium bromide, L-buthionine sulfoximine (BSO), manganese chloride, bovine serum albumin (BSA), 5,5'-dithio-bis(2-nitrobenzoic acid), 2-vinylpyridine (2-VP), glutathione reduced form, L-glutathione oxidized form, poly-L-lysine, nitroblue tetrazolium (NBT), 1-chloro-2,4-dinitrobenzene (CDNB), ethylenediaminetetraacetic acid (EDTA), xanthine, xanthine oxidase, $\beta$-NADPH, and anti- $\alpha$-tubulin antibodies were purchased from Sigma-Aldrich (St. Louis, MO, USA). Trypsin inhibitor, penicillin-streptomycin, trypan blue, fetal bovine, and horse serum were purchased from Gibco (Life Technologies, Grand Island, NY, USA). Tin mesoporphyrin (SnMP) was from Frontier Scientific Inc. (Logan, UT, USA). Monochlorobimane and Hoechst 33258 stain were from Fluka (Sigma-Aldrich). Fluorescein isothiocyanate (FITC) conjugated secondary antibodies were purchased from Jackson Immunoresearch Laboratories (West Grove, PA, USA). Anti-HO-1 antibodies were acquired from Enzo Life Sciences, Inc. 5-(and 6-)Carboxy-2',7'-dichlorodihydrofluorescein diacetate (carboxy-DCFDA) and fluorescein diacetate (FDA) were purchased from Molecular Probes (Life Technologies). Horseradish peroxidase (HRP) conjugated donkey anti-rabbit or goat anti-mouse IgG was from GE Healthcare Biosciences (Pittsburgh, PA, USA) and Invitrogen (Life Technologies), respectively. Anti-Nrf2 and antiproliferating cell nuclear antigen (PCNA) antibodies were from Abcam (Cambridge, MA, USA). The TransAM ELISA kit for Nrf2 (catalogue no. 50296) and Nuclear extract kit (catalogue no. 40010) were purchased from Active Motif Inc. (Carlsbad, CA, USA). Bio-Rad Protein Assay Dye reagent concentrate was purchased from Bio Rad Laboratories (Hercules, CA, USA). All other reagents were of analytical grade and were commercially available.

2.2. Primary Cultures of CGNs. Primary cell cultures were obtained from 7-day-old rat cerebellum as previously described [29-31]. Experiments were performed using cells cultured for 9 days in vitro (DIV). The animals were handled and cared with an agreement to the guidelines of the Normal Official Mexicana for the use and care of laboratory animals (NOM-062-ZOO-1999) and for the disposal of biological residues (NOM-087-ECOL-1995). The protocol was approved by the local ethics committee (FQ/CICUAL/059/13). CGNs were cultured in BME supplemented with $50 \mu \mathrm{g} / \mathrm{mL}$ of gentamicin sulfate, $2 \mathrm{mmol} / \mathrm{L}$ of L-glutamine, and $10 \%$ heatinactivated fetal bovine serum. Cytosine arabinoside $(10 \mu \mathrm{M})$ was added $24 \mathrm{~h}$ after plating. Glucose $(5 \mathrm{mM})$ was added to the cultures on $4 \mathrm{DIV}$. CGNs were maintained at $37^{\circ} \mathrm{C}$ in a $5 \% \mathrm{CO}_{2}$ atmosphere. Purity of the cultures using this method is around 95\% [31]. 
2.3. Culture Treatments. In order to induce oxidative stress, CGNs were incubated with 5-50 $\mu \mathrm{M}$ hemin in Krebs Ringer medium for $1 \mathrm{~h}$, hemin was removed, and CGNs were incubated with culture medium for $24 \mathrm{~h}$. Concentrated hemin solution $(8 \mathrm{mM})$ was dissolved in $40 \mathrm{mM}$ sodium hydroxide and maintained protected from light. This solution was used to prepare the working solution in $10 \mathrm{mM}$ phosphate buffer, $\mathrm{pH}$ 7.4. The effect of curcumin on cell viability was established. Concentrated curcumin solution $(10 \mathrm{mM})$ was dissolved in DMSO and maintained protected from light. This solution was used to prepare the working solution in $10 \mathrm{mM}$ phosphate buffer, $\mathrm{pH}$ 7.4. This solution was added directly to the culture medium to reach the desired final concentrations. CGNs were incubated with increasing concentrations of curcumin $(0-50 \mu \mathrm{M})$ for $24 \mathrm{~h}$. At the end of this time, the viability of cells was measured. In further experiments, the potential protective effect of curcumin on CGNs was determined. CGNs were incubated for $24 \mathrm{~h}$ with 5,10 , and $15 \mu \mathrm{M}$ of this antioxidant before the addition of hemin and its viability was evaluated $24 \mathrm{~h}$ later.

2.4. Cell Viability Measurement. Colorimetric MTT and FDA fluorescent assays were used to measure cell viability. MTT is reduced to formazan by the activity of mitochondrial dehydrogenases, and the absorbance is directly proportional to viable cells [30]. On the other hand, FDA is a cell permeable probe that esterases of living cells convert it to the fluorescent compound fluorescein. Cells were treated with $12 \mu \mathrm{M}$ FDA for $5 \mathrm{~min}$ at $37^{\circ} \mathrm{C}$ and after washing fluorescence was quantified in a Synergy HT MultiMode Microplate Reader (Biotek, Winooski, VA, USA) using the following wavelengths filters: excitation $485 / 20 \mathrm{~nm}$ and emission $528 / 20 \mathrm{~nm}$. Cell viability was expressed as a percentage of MTT reduction or fluorescence emission. Viability of control cells (without treatment) was considered as $100 \%$. The value of cells incubated with different treatments was compared with that of control cells. The correlation coefficient between MTT and FDA methods was also calculated.

2.5. Western Blot Analysis. At the end of each treatment, cells were harvested in $50 \mathrm{mM}$ phosphate buffer ( $\mathrm{pH} 7.4$ ) with $0.1 \%$ triton X-100. The total amount of protein was determined using the Lowry method with BSA as a standard. Western blot analysis was performed as previously described [29]. Protein $(30 \mu \mathrm{g})$ was separated on SDS-PAGE and transferred to polyvinylidene difluoride membranes (EMD Millipore Corporation, Billerica, MA, USA). After blocking with 5\% nonfat milk in blocking TBS-T buffer (Tris, $\mathrm{pH} 7.4$ containing $0.1 \%$ Tween-20), membranes were incubated with anti-HO-1 or anti- $\alpha$-tubulin antibodies at $4^{\circ} \mathrm{C}$ overnight in TBS-T. Afterward, membranes were washed and probed with horseradish peroxidase-conjugated donkey anti-rabbit or goat anti-mouse IgG for $1 \mathrm{~h}$ at room temperature. Bands were detected by chemiluminescence using the Millipore ECL detection kit and revealed on autoradiographic films. Densitometry was performed with ImageJ 1.47 (National Institutes of Health, USA).
2.6. Determination of Reactive Oxygen Species (ROS). The measurement of ROS was performed by using the fluorescent probes carboxy-DCFDA and dihydroethidium as previously described [32]. The compound carboxy-DCFDA is deacetylated by esterases, oxidized by ROS and reactive nitrogen species, and converted to the fluorescent compound 5-(and 6-)carboxy-2,7-dichlorofluorescein (carboxy-DCF), staining the cell cytoplasm with bright green fluorescence. Dihydroethidium is oxidized to ethidium in the cytosol mainly by superoxide anion and is then retained within the cell nucleus because of its interaction with DNA and thus staining the nucleus with bright red fluorescence [33].

After cell culture treatments, both fluorescent probes were loaded in Ringer Krebs solution during 20 min. Cells were examined under an epifluorescence microscope using the fluorescent cubes B-2A/C-excitation 450 to $490 \mathrm{~nm}$ and G-2A-excitation 510 to $560 \mathrm{~nm}$ from Nikon Instruments Inc. (Melville, NY, USA) for the carboxy-DCF and ethidium detection, respectively [31]. The intensity of fluorescence was measured in five random and different fields per well per condition in three independent experiments, using the NIS Elements Imaging software (Nikon Instruments Inc.).

\subsection{Measurement of Glutathione Content}

2.7.1. Total Glutathione (GSH + GSSG) and GSSG Analysis. GSH and GSSG levels were measured in CGNs extracts using the GSH reductase enzyme method [34]. This assay is based on the reaction of GSH and thiol-mediated which produces the 5,5'-dithio-bis (2 nitrobenzoic acid) (DTNB) to 5-thio2-nitrobenzoic acid (TNB), detectable at $\lambda=412 \mathrm{~nm}$. The test is specific to GSH due to the specificity of the GSH reductase enzyme to GSH: the rate of accumulation of TNB is proportional to the concentration of GSH in the sample. Briefly, cell extract was diluted 1:2 with KPE buffer $(0.1 \mathrm{M}$ potassium phosphate, $5 \mathrm{mM}$ disodium EDTA, $\mathrm{pH}$ 7.5) prior to the addition of freshly prepared DTNB $(2.5 \mathrm{mM})$ and GSH reductase solutions $(250 \mathrm{U} / \mathrm{mL})$. Following the addition of $\beta$-NADPH, the absorbance $(\lambda=412 \mathrm{~nm})$ was measured immediately at $30 \mathrm{~s}$ intervals for $2 \mathrm{~min}$. The rate of change in absorbance was compared to that for GSH standards. The measurement of GSSG in each sample was identical to that used for the measurement of GSH, but with a previous treatment of the sample with 2 -VP, which reacts out with GSH.

2.8. GSH Reduced Form. GSH levels were measured using monochlorobimane as previously described [35]. The fluorescence was measured using excitation and emission wavelengths 385 and $478 \mathrm{~nm}$, respectively, using a Synergy HT multimode microplate reader.

2.9. Activity of Antioxidant Enzymes. GR activity was tested using GSSG as substrate and by measuring the disappearance of NADPH at $340 \mathrm{~nm}$ each minute for $3 \mathrm{~min}$. One unit of GR was defined as the amount of enzyme that oxidizes $1 \mu \mathrm{mol}$ of $\mathrm{NADPH} / \mathrm{min}$. GST activity was assayed in a mixture containing GSH and CDNB and measuring the increase of optical density at $340 \mathrm{~nm}$ each minute for $3 \mathrm{~min}$. One unit of GST 
was defined as the amount of enzyme that conjugates $1 \mu \mathrm{mol}$ of CDNB with GSH per minute. Total SOD activity was assayed spectrophotometrically at $560 \mathrm{~nm}$ by a method using xanthine and xanthine oxidase for generation of superoxide anion and NBT as the indicator reagent [28]. The amount of protein that inhibited maximum NBT reduction to $50 \%$ was defined as $1 \mathrm{U}$ of SOD activity. All the activities were expressed as $\mathrm{U} / \mathrm{mg}$ protein.

2.10. Immunocytochemical Localization of Nrf2. CGNs were seeded on 12-well plates containing glass coverslips treated with $0.025 \%$ poly-l-lysine and grown for 9 days. Curcumin was added for $1,4,6,16$, and $24 \mathrm{~h}$ or $24 \mathrm{~h}$ before hemin treatment. Next, cells were washed with phosphate buffer saline (PBS) and fixed with $4 \%$ paraformaldehyde for $15 \mathrm{~min}$ at room temperature, permeabilized with $0.5 \%$ triton X-100 for 20 min, blocked with 3\% BSA-0.5\% triton X-100-3\% horse serum, and incubated with anti-Nrf2 antibody (in 1\% BSA-1\% triton $\mathrm{X}-100)$ for $2.5 \mathrm{~h}$ at room temperature. The coverslips were incubated overnight in the dark at $4^{\circ} \mathrm{C}$ with FITC conjugated secondary antibody and washed with PBS. A nuclear counterstaining was made with a solution of $0.2 \mu \mathrm{g} / \mathrm{mL}$ Hoechst 33258 stain for $1 \mathrm{~min}$ and mounting on a slide using Fluoromount Aqueous Mounting Medium [36]. Inverted fluorescence microscope (Nikon Eclipse TS-100F) was used with B-2A/C filter for FITC fluorescence and UV-2A filter for Hoechst signal. The images were acquired with a Nikon Digital Sight DS-Fi 1 camera. Five random images were taken for each well for condition in three independent experiments. NIS Elements Imaging software (Nikon Instruments Inc.) was used for quantification.

2.11. Nuclear Extraction and Nrf2 Binding Activity Assay. Nuclear extracts were prepared from CGNs cells using the Nuclear Extract Kit of Active Motif according to the manufacturer's guidelines. Protein concentration in samples was measured using the Bio-Rad Protein Assay Dye reagent. An ELISA-based assay consisting of an immobilized oligonucleotide containing the ARE consensus-binding site ( $5^{\prime}$-GTCACAGTGACTCAGCAGAATCTG- $\left.3^{\prime}\right)$ was used to measure Nrf2 DNA binding activity. Nrf2 from $20 \mu \mathrm{g}$ of nuclear extract was allowed to bind to the ARE on 96-well plates. A primary antibody against $\mathrm{Nrf2}$ was then used to detect bound Nrf2. A secondary antibody conjugated to HRP provided a colorimetric readout at $450 \mathrm{~nm}$. Nuclear extracts from COS-7 cells transfected with Nrf2 were included as the positive control. The presence of PCNA and absence of protein were used as a measure of the purity of nuclear extracts.

2.12. Statistics. Data were expressed as mean \pm SEM. They were analyzed with the software Prism 5 (GraphPad, San Diego, CA, USA) by one-way analysis of variance (ANOVA) followed by Bonferroni multiple comparison test or Dunnett test, as appropriate; $P<0.05$ was considered significant. " $n$ " indicates the number of independent experiments.

\section{Results}

3.1. Hemin Induces Cytotoxicity and ROS Production in CGNs. It was shown that CGNs exposure to hemin induced a decrease in the viability in a concentration-dependent way from 20 to $50 \mu \mathrm{M}$ after $1 \mathrm{~h}$ of incubation, using two methods: FDA fluorescence and MTT reduction (Figures 1(a) and 1(b)). These methods showed a high correlation $\left(R^{2}=0.993, P<\right.$ 0.0001 ) (Figure 1(c)). Incubation with $30 \mu \mathrm{M}$ hemin for $1 \mathrm{~h}$ decreased cell viability by about $50 \%$ of control quantified with both assays $(P<0.05)$. Also, cell morphology was verified in bright field micrographs (data not shown). The CGNs treated with the vehicle or $10-20 \mu \mathrm{M}$ hemin were round and dark with networks of notable processes, but the cells treated with a higher concentration of hemin (30-50 $\mu \mathrm{M})$ showed morphological alterations, the regular shaped cell bodies seen before were replaced by shrunken, irregular soma and the presence of thin and fragmented neurites. Afterwards, the oxidative effect of hemin was evaluated (Figures 1(d) and 1(e)). Incubation with $30 \mu \mathrm{M}$ hemin increased fluorescence of carboxy-DCF and ethidium by 3.5 - and 4.4 -fold $(P<0.05)$, respectively, indicating a marked ROS increase in CGNs (Figure 1(e)).

3.2. Curcumin Protects against Hemin-Induced Cytotoxicity and ROS Production. Lower concentrations of curcumin (0$40 \mu \mathrm{M})$ were unable to induce morphological changes in CGNs (Figure 2(a)). Round and dark cells and a network of processes are prominent throughout the field. Nevertheless, curcumin at higher concentration $(50 \mu \mathrm{M})$ induced morphological changes such as the presence of thin and fragmented neurites. Cell viability remained unchanged at concentrations ranging from 5 to $30 \mu \mathrm{M}$; however, the viability at $50 \mu \mathrm{M}$ curcumin after $24 \mathrm{~h}$ incubation was decreased by $20 \%$ and $21 \%$ using the MTT and FDA assays, respectively (Figure 2(b), $P<0.05)$. The potential protective effect of curcumin against hemin-induced damage was then assessed. Curcumin significantly decreased hemin-induced cell death in CGNs at all concentrations tested $(P<0.05)$. The percentage of prevention of cell death was 45,47 , and 49 with 5,10 , and $15 \mu \mathrm{M}$ curcumin, respectively (Figure 2(c)). Moreover, curcumin (5, 10 , or $15 \mu \mathrm{M}$ ) was added to the culture $24 \mathrm{~h}$ prior to the hemin exposure, and ROS production was measured by fluorometry (Figures 3(a) and 3(b)). It was found that curcumin was able to block the hemin-induced ROS increase $(P<0.05)$ and that curcumin alone slightly increased ROS (Figures 3(a) and $3(\mathrm{~b}))$. Interestingly, the preincubation of curcumin for 1 or $2 \mathrm{~h}$ and coincubation of curcumin with $30 \mu \mathrm{M}$ hemin for $1 \mathrm{~h}$ was unable to protect against the hemin-induced toxicity in CGNs on $24 \mathrm{~h}$ (data not shown).

3.3. Curcumin Increases HO-1 Expression and GSH Levels in CGNs. Curcumin induced HO-1 protein levels in a concentration-dependent manner (Figure 4(a)). Exposure of CGNs to $5 \mu \mathrm{M}$ curcumin by $24 \mathrm{~h}$ increased HO- 1 levels by threefold compared to control $(P<0.05)$. The maximum level of expression of 5.4- and 4.9-fold was reached at 20 and $30 \mu \mathrm{M}$, respectively (Figure 4(a)). Furthermore, 


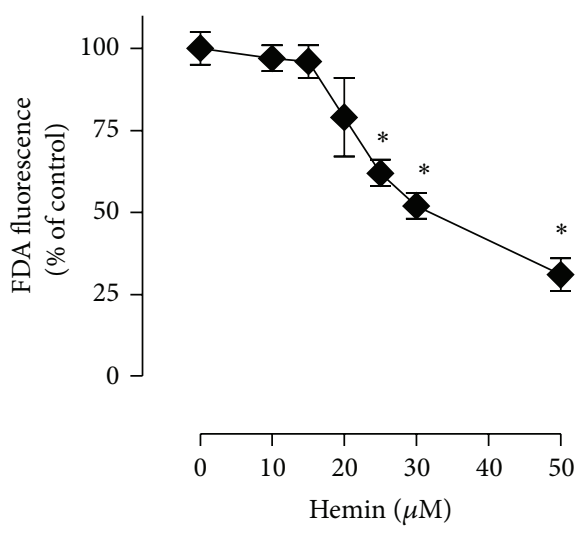

FDA

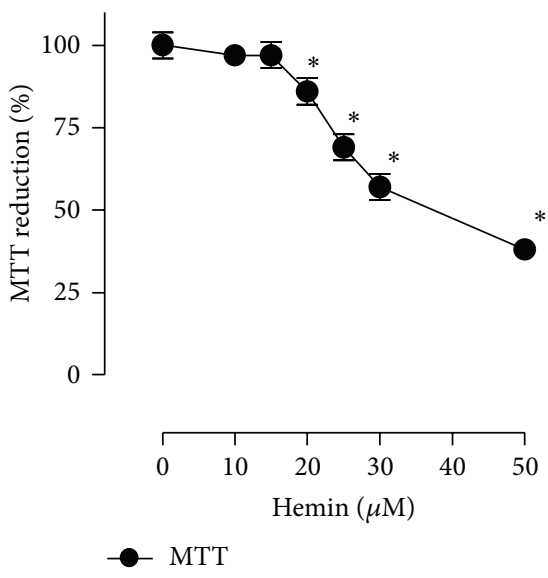

(b)

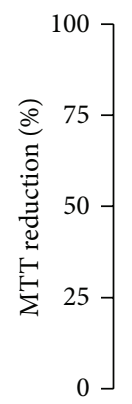

\begin{tabular}{rrrrrr}
\hline & & 1 & 1 & \\
0 & 20 & 40 & 60 & 80 & 100 \\
& FDA fluorescence $(\%)$
\end{tabular}

(c)

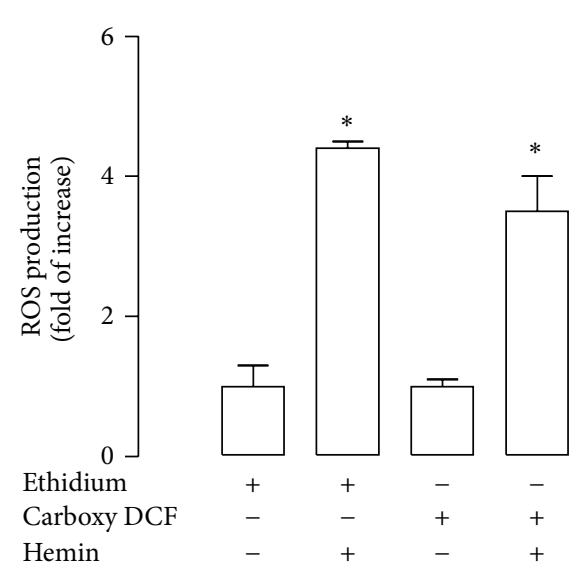

(e)
Hemin

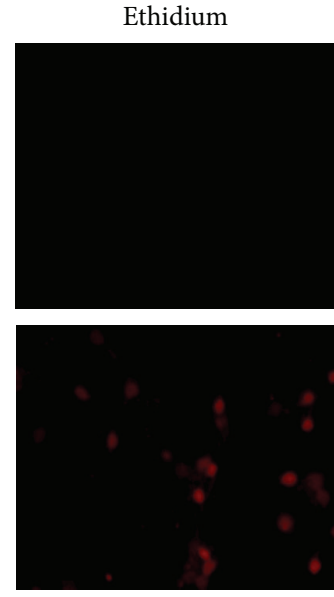

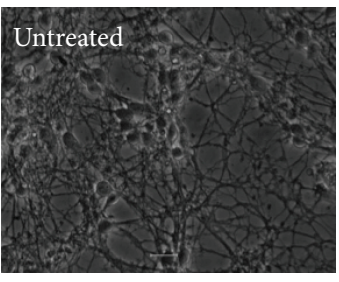

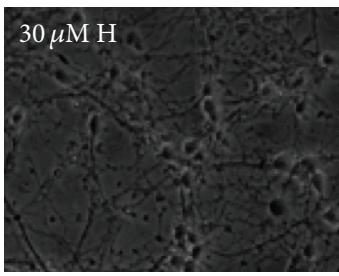

(d)
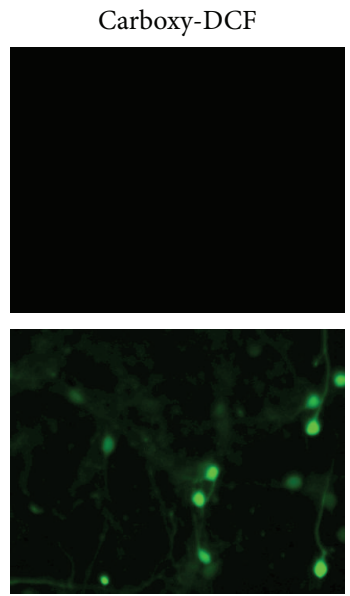

FIGURE 1: Hemin induced neuronal death and reactive oxygen species (ROS) production in cerebellar granule neurons (CGNs). Cultures were exposed to hemin for $1 \mathrm{~h}$ followed by recovery in growth medium for $24 \mathrm{~h}$. The data were obtained after this time. Viability was assessed by (a) fluorescein diacetate (FDA) fluorescence and (b) 3-[4,5-dimethylthiazol-|2-yl)]-2,5-diphenyl-tetrazolium bromide (MTT) reduction. (c) Pearson correlation index between FDA and MTT assays. (d) ROS production was evaluated after $1 \mathrm{~h}$ of incubation with $30 \mu \mathrm{M}$ hemin. Bright-field (left panel, H: hemin), 5-(and 6-)carboxy-2 ${ }^{\prime}, 7^{\prime}$-dichlorofluorescein (carboxy-DCF, middle panel), and ethidium (right panel). The same field is shown in each condition. (e) Intensity of carboxy-DCF or ethidium fluorescence was measured in five different fields per well per condition and was quantified using CGNs with the respective probe as a control. Data are expressed as mean \pm SEM, $n=3-5$. ${ }^{*} P<0.05$ versus $0 \mu \mathrm{M}$ hemin.

$15 \mu \mathrm{M}$ curcumin induced a time-dependent increase of HO1 protein levels starting at $4 \mathrm{~h}$; the increase was significant at 8,16 , and $24 \mathrm{~h}$ (Figure $4(\mathrm{~b}), P<0.05)$. Moreover, curcumin induced a significant increase of GSH and $[\mathrm{GSH}]+$ [GSSG] levels after $24 \mathrm{~h}$ of incubation at all tested curcumin concentrations ( 5 to $30 \mu \mathrm{M}$ ) in a concentration-dependent way (Figures $4(\mathrm{c})$ and $4(\mathrm{~d}), P<0.05)$. GSH levels were also evaluated in CGNs cultures incubated with curcumin for $24 \mathrm{~h}$ before hemin treatment. First, curcumin and curcumin plus hemin significantly increased GSH levels (Figure 5(a), $P<$ $0.05)$. Hemin significantly increased GSSG levels (ninefold) (Figure 5(b), $P<0.05$ ) and decreased [GSH]/[GSSG] ratio (Figure 5(c), $P<0.05$ ). Moreover [GSH] + [GSSG] levels were increased with curcumin alone, curcumin plus hemin, and hemin alone (Figure 5(d), $P<0.05$ ).
3.4. The Inhibitors of the HO System and GSH Synthesis Abolish the Protection Induced by Curcumin in Hemin-Treated CGNs. For the assessment of the mechanisms by which curcumininduced protection, the following inhibitors were used: SnMP, an inhibitor of the HO system and BSO, an inhibitor of $\gamma$-GCL, the rate-limiting enzyme of GSH synthesis. Cells were incubated 15 min with $10 \mu \mathrm{M}$ SnMP and then exposed to $30 \mu \mathrm{M}$ hemin. The incubation with SnMP or curcumin alone or SnMP/curcumin had no effect on cell viability. In contrast, it is evident that coincubation with SnMP/curcumin with or without hemin significantly affected the viability of CGNs and blocked cell protection (Figure 6(a), $P<0.05$ ). On the other hand, the CGNs pretreated for $24 \mathrm{~h}$ with $15 \mu \mathrm{M}$ curcumin were first incubated with $25 \mu \mathrm{M}$ BSO for $1 \mathrm{~h}$ and then exposed to $30 \mu \mathrm{M}$ hemin. In this condition, cell death induced 

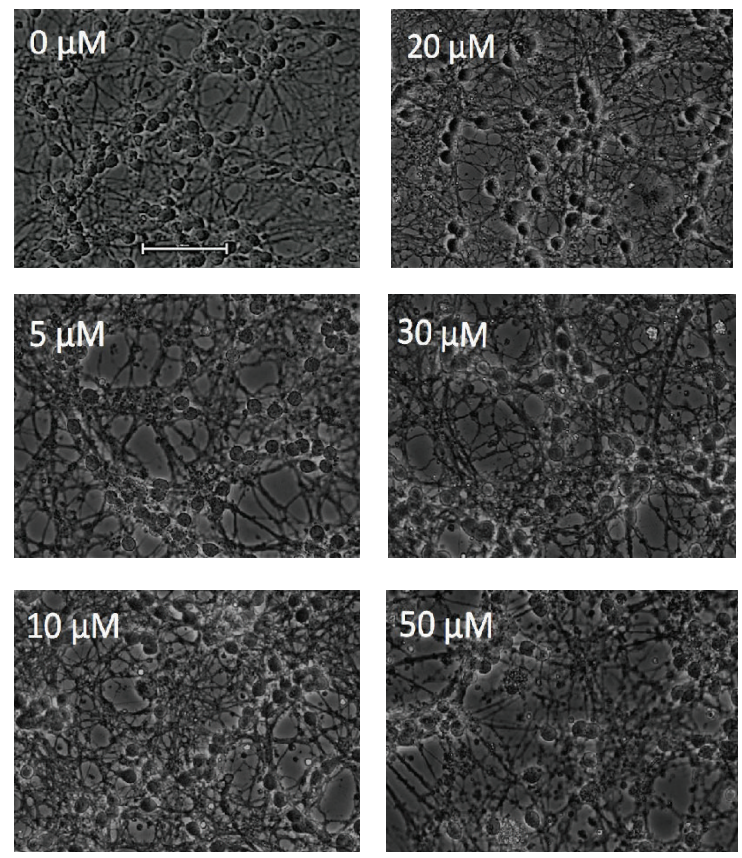

(a)

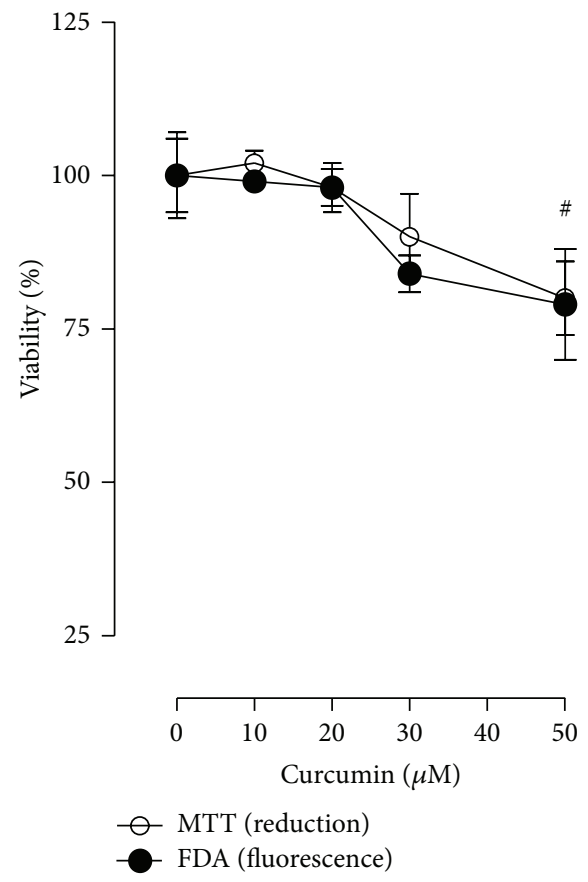

(b)

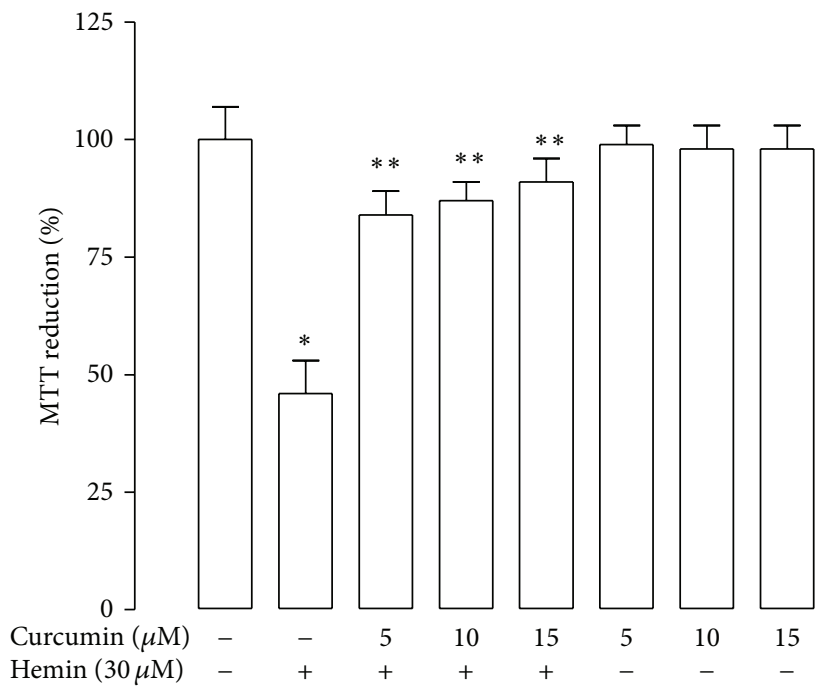

(c)

FIGURE 2: Effect of curcumin on cerebellar granule neurons (CGNs) viability in absence or presence of hemin. (a) Bright field representative images (40x) of CGNs treated with curcumin $(0-50 \mu \mathrm{M}$ for $24 \mathrm{~h})$. Scale bar represents $10 \mu \mathrm{m}$ and applies to all panels. (b) Viability was quantified by fluorescein diacetate (FDA) fluorescence ( $\circ$ ) and 3-[4,5-dimethylthiazol-|2-yl)]-2,5-diphenyl-tetrazolium bromide (MTT) reduction $(\bullet)$. (c) CGNs were incubated with 5,10 , and $15 \mu \mathrm{M}$ curcumin for $24 \mathrm{~h}$ before the addition of $30 \mu \mathrm{M}$ hemin for $1 \mathrm{~h}$. Subsequently hemin was replaced by fresh medium and the incubation was continued up to $24 \mathrm{~h}$. Finally, cell viability was quantified by MTT reduction and expressed as percentage of control. Data are expressed as mean $\pm \mathrm{SEM}, n=6 .{ }^{\#} P<0.05$ versus $0 \mu \mathrm{M},{ }^{*} P<0.05$ versus control (untreated), ${ }^{* *} P<0.05$ versus hemin.

by hemin was evidently exacerbated during GSH depletion induced by $\mathrm{BSO}(P<0.05)$. Cell viability was unaffected by incubation with $\mathrm{BSO}$ or curcumin alone or $\mathrm{BSO} /$ curcumin (Figure 6(b)).

3.5. Nrf2 Was Activated by Curcumin and Localized in Nucleus in Neuronal Cultures. Curcumin was able to bring about nuclear translocation of Nrf2 in a time-dependent way.
Nrf2 was localized in nucleus after incubation with $15 \mu \mathrm{M}$ curcumin by $4,6,16$, and $24 \mathrm{~h}$ (C $4 \mathrm{~h}, 6 \mathrm{~h}, 16 \mathrm{~h}$, and $24 \mathrm{~h}$, Figure 7(a)). Furthermore, signal of Nrf2 was seen $24 \mathrm{~h}$ after $24 \mathrm{~h}$ of incubation with curcumin (recovery time) (C $24 \mathrm{~h}+$ $24 \mathrm{~h}$, Figure $7(\mathrm{a}))$.

It is interesting to mention that fluorescent signal of Nrf2 significantly colocalizes with nuclear signal at 16 and $24 \mathrm{~h}$ of incubation (Figure 7(a)). Also, the signal of $\mathrm{Nrf2}$ was shown 

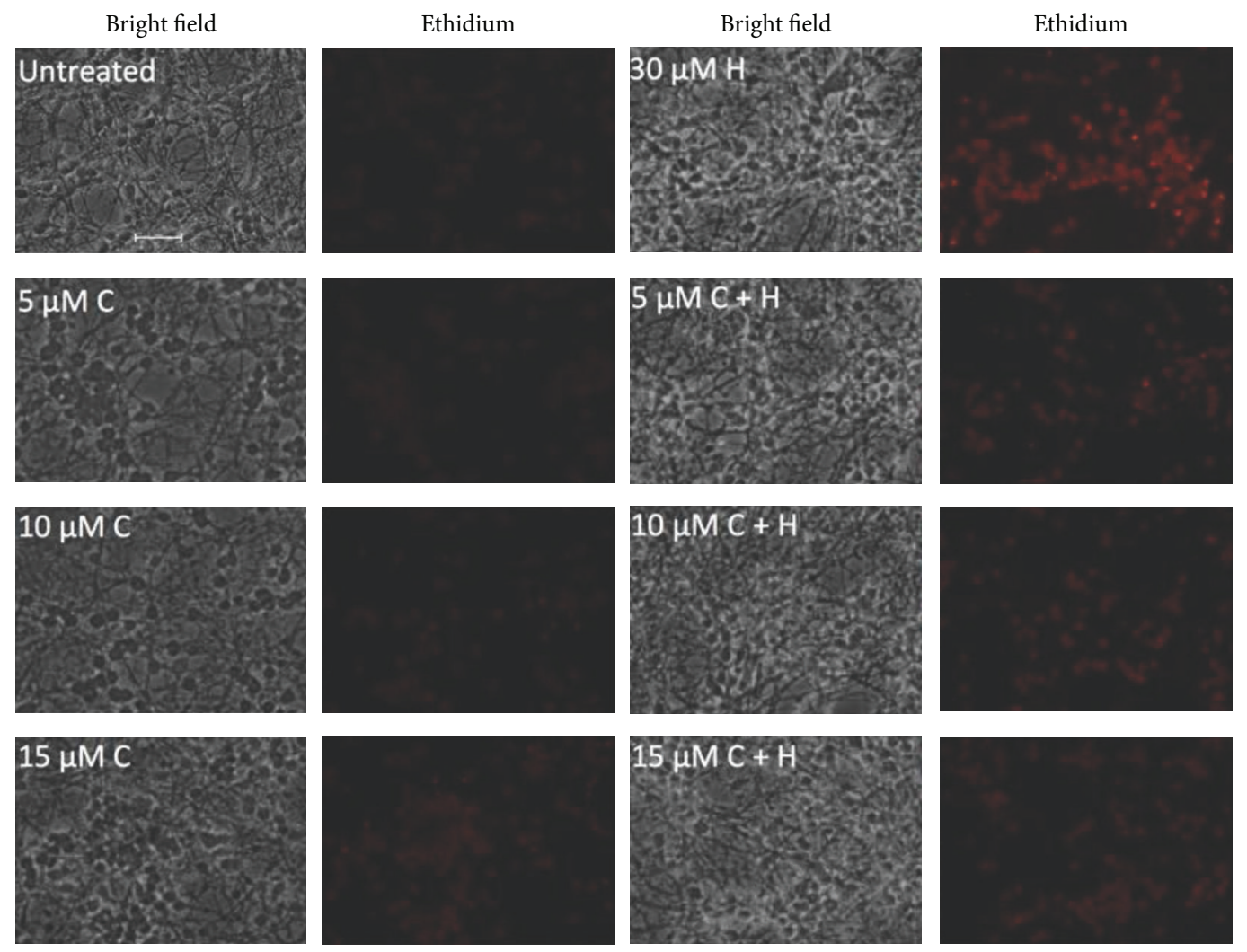

(a)

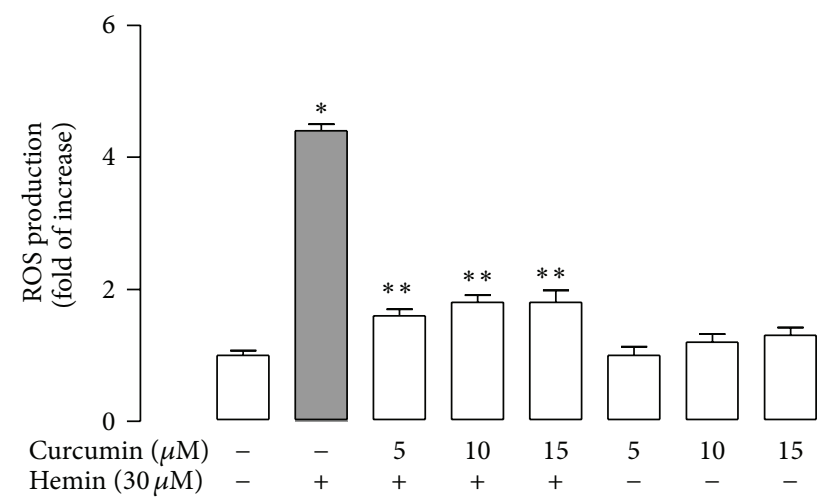

(b)

FIGURE 3: Effect of curcumin (C) pretreatment on hemin (H) induced reactive oxygen species (ROS) production in CGNs. (a) Representative images (40x) after $24 \mathrm{~h}$ of treatment with 5, 10, and $15 \mu \mathrm{M}$ curcumin and exposed to $30 \mu \mathrm{M}$ hemin for $1 \mathrm{~h}$. Bright-field (left panel) and ethidium fluorescence (right panel). The same field is shown in each condition. Scale bar represents $10 \mu \mathrm{m}$ and applies to all panels. (b) Intensity of ethidium fluorescence was measured in 5 different fields per well per condition. Data are expressed as mean $\pm \mathrm{SEM}, n=3 .{ }^{*} P<0.05$ versus control, ${ }^{* *} P<0.05$ versus hemin.

in cells treated with curcumin ( $24 \mathrm{~h}$ of incubation) and hemin (C $24 \mathrm{~h}+\mathrm{H}$, Figure $7(\mathrm{a}))$ and $24 \mathrm{~h}$ of recovery time $(\mathrm{C} 24 \mathrm{~h}+$ $\mathrm{H}+24 \mathrm{~h}$, Figure $7(\mathrm{a}))$. Hemin with or without $24 \mathrm{~h}$ of recovery time $(\mathrm{H}+24 \mathrm{~h})$ induced a nonsignificant accumulation of Nrf2 in the nucleus, but when curcumin was preincubated, strong levels of induction were observed (Figure 7(b), $P<$ 0.05). Additionally, using the TransAM ELISA kit, the nuclear Nrf2 binding activity was assessed in CGNs from control, and $15 \mu \mathrm{M}$ curcumin for $24 \mathrm{~h}, 15 \mu \mathrm{M}$ curcumin for $24 \mathrm{~h}$ of incubation plus hemin and hemin alone. A significant increase in Nrf2 activity was seen when curcumin was present (Figure 7(c), $P<0.05$ ), which is consistent with the immunocytochemical data (Figures 7(a) and 7(b)). COS7 cells transfected with Nrf2 were used as a positive control (Figure 7(c), last column) of the assay. The activity of this positive control showed the reliability of this assay. 

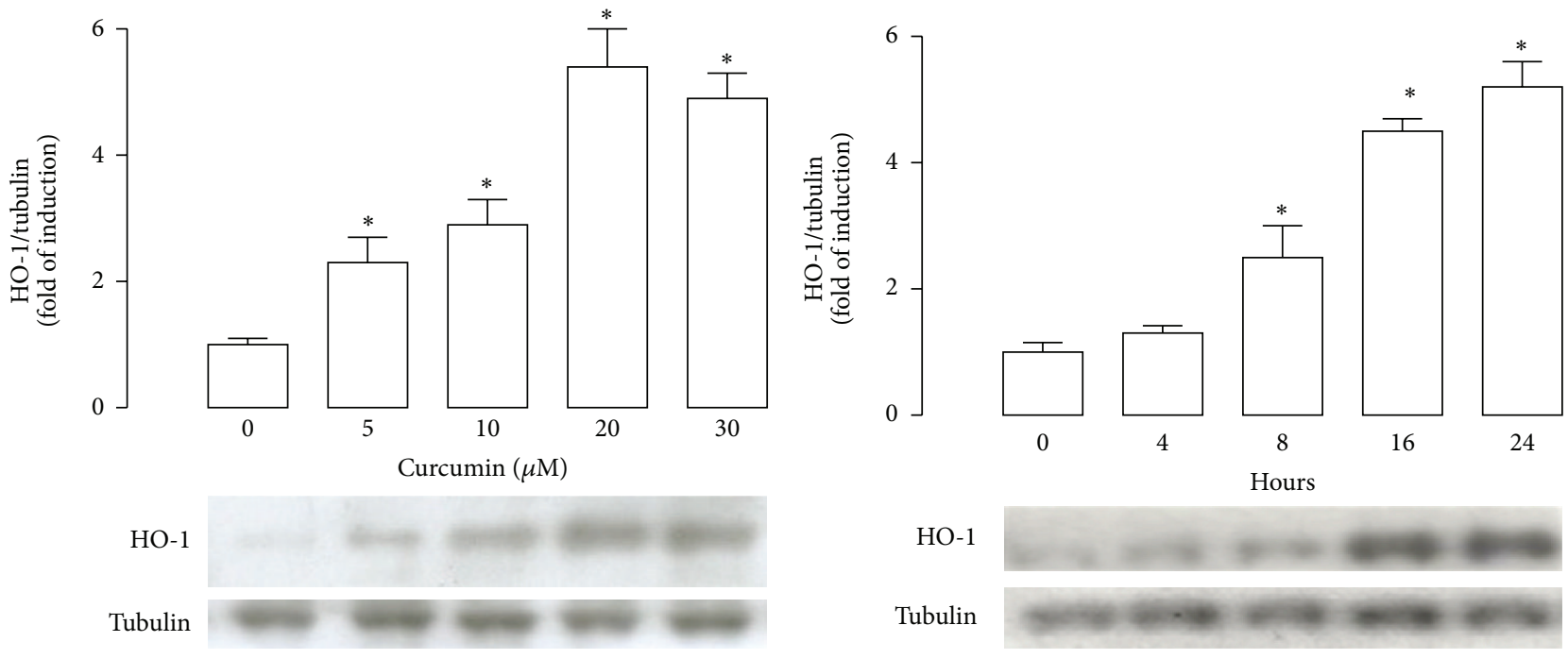

HO-1

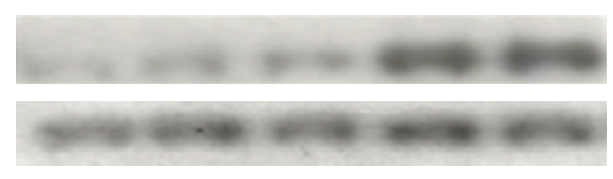

(a)

(b)

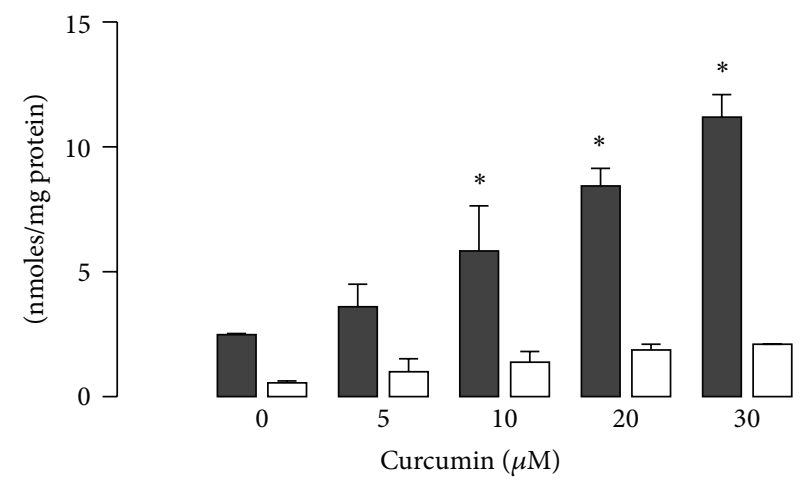

[GSH]

[GSSG]

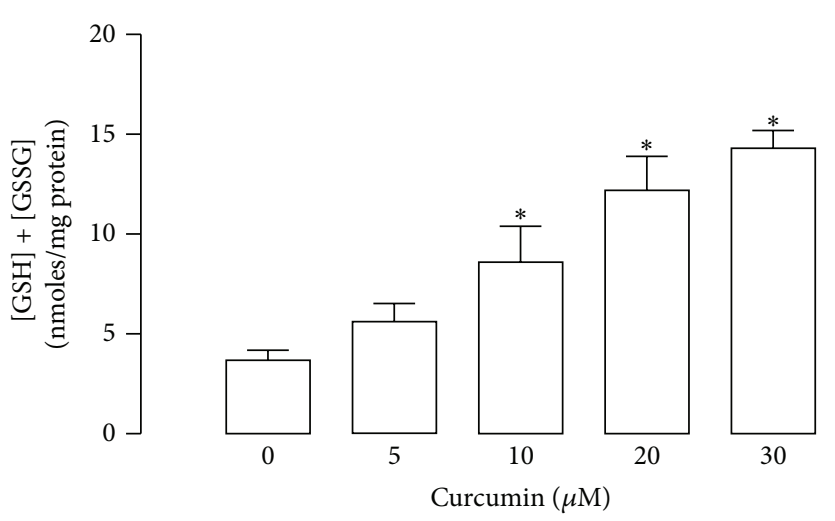

(c)

(d)

FIGURE 4: Curcumin increases heme oxygenase-1 (HO-1) protein and glutathione (GSH) and glutathione disulfide (GSSG) levels in CGNs. (a) Curcumin induced HO-1 expression in a concentration (after $24 \mathrm{~h}$ incubation) and (b) time-dependent (with $15 \mu \mathrm{M}$ curcumin) manner. Upper panels show graphs of densitometric analysis (HO-1/tubulin) from each band; lower panels show immunoblot of HO-1 and loading control with tubulin. (c) GSH and GSSG levels were determined $24 \mathrm{~h}$ after treatment with 5-30 $\mu \mathrm{M}$ curcumin. (d) [GSH] + [GSSG] content was evaluated $24 \mathrm{~h}$ after incubation with curcumin. Data are expressed as mean $\pm \mathrm{SEM}, n=4-5 .{ }^{*} \mathrm{P}<0.05$ versus $0 \mu \mathrm{M}$ curcumin or 0 hours.

3.6. Curcumin Pretreatment Induces the Activity of GR, GST, and SOD in CGNs. The activity of the antioxidant enzymes was measured in cells incubated for $24 \mathrm{~h}$ with $15 \mu \mathrm{M}$ curcumin and treated with $30 \mu \mathrm{M}$ hemin for $1 \mathrm{~h}$. Additionally, enzyme activity was determined $24 \mathrm{~h}$ after (recovery time) both compounds were removed. Activity of GR, GST, and SOD was increased in CGNs treated with curcumin for $24 \mathrm{~h}$ (Figure 8). GR activity was significantly increased in the recovery time after incubation with curcumin or curcumin/hemin (Figure $8(\mathrm{a}), P<0.05$ ). In addition, the activity of GST and SOD was only significantly increased after $24 \mathrm{~h}$ of curcumin incubation $(P<0.05)$. A nonsignificant increase of the activity of GST and SOD was observed with curcumin or cotreatment with curcumin/hemin with recovery time of $24 \mathrm{~h}$ after incubation (Figures $8(\mathrm{~b})$ and $8(\mathrm{c})$ ).

\section{Discussion}

The purpose of this work was to study the effect of curcumin against the hemin-induced damage in CGNs. Protection by curcumin of different cells in culture and rat models against a variety of damages has been previously described [28, 37-39]; however, no studies have tested the potential protective effect of curcumin against hemin toxicity in neurons.

It has been described in CGNs that hemin is toxic by itself. First, hemin can be accumulated in neurons (in part by heme carrier protein 1) and secondly, $\mathrm{Fe}^{3+}$ was not the main effector of the damage because the use of iron chelators was unable to prevent hemin toxicity. Also, HO-1 expression was not augmented in CGNs [24]. Our data also show hemin toxicity, in fact an increase of ROS production and 


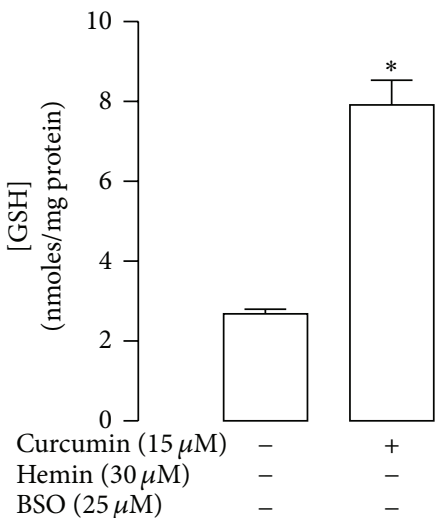

(a)
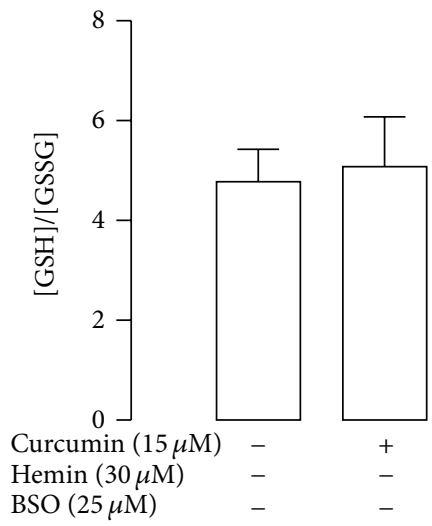
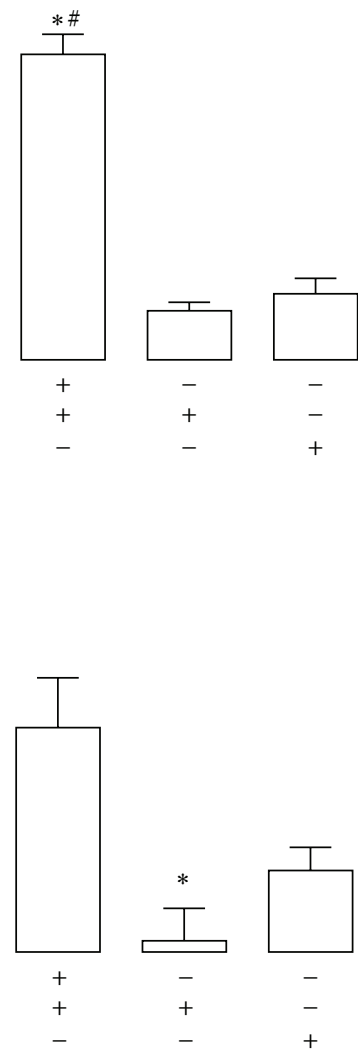

(c)

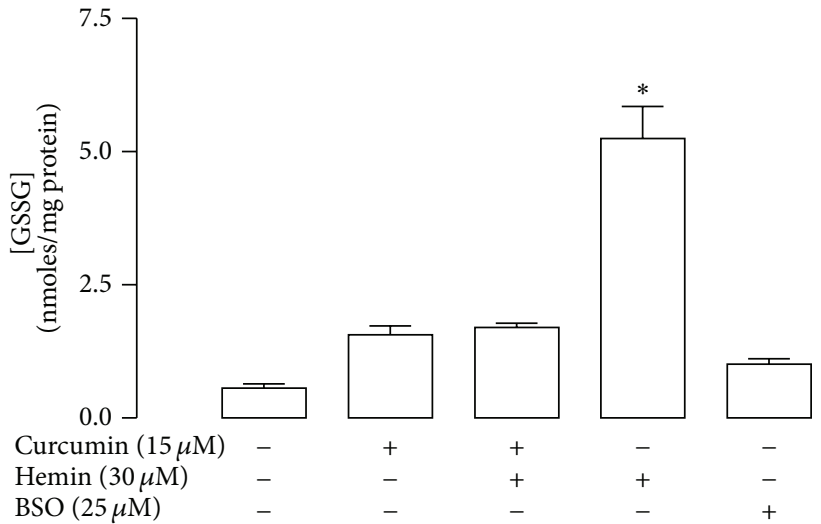

(b)

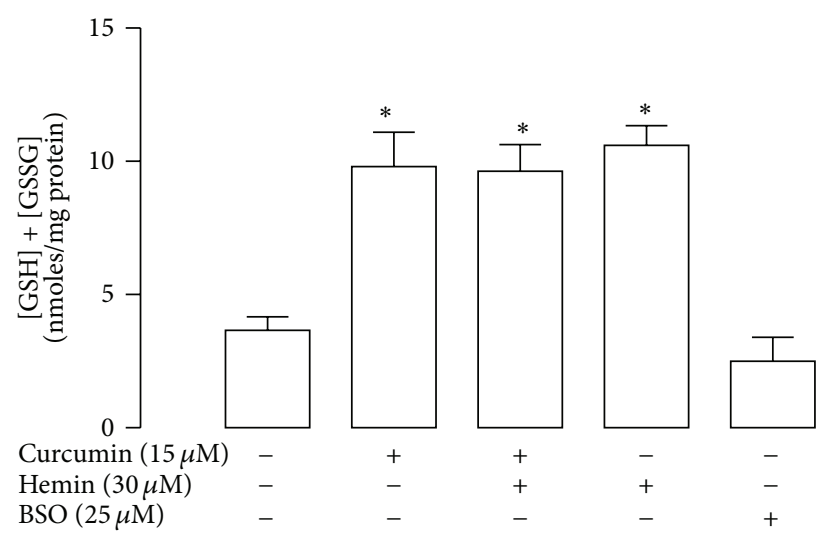

(d)

FIGURE 5: Curcumin prevents hemin-induced changes in glutathione (GSH) and glutathione disulfide (GSSG) levels in CGNs. Cells were incubated with $15 \mu \mathrm{M}$ curcumin for $24 \mathrm{~h}$. The culture medium was removed and $30 \mu \mathrm{M}$ hemin was added for $1 \mathrm{~h}$. Hemin was replaced by fresh medium and incubation was continued up to $24 \mathrm{~h}$. (a) GSH levels were assayed with monochlorobimane. (b) GSSG levels were quantified by using 2-vinylpriridine (2-VP). (c) [GSH]/[GSSG] ratio was calculated. (d) [GSH] + [GSSG] content was quantified by 5,5'-dithio-bis(2nitrobenzoic acid) (DTNB). Buthionine sulfoximine (BSO), an inhibitor of GSH synthesis, was used as a control. Data are expressed as mean \pm SEM, $n=5 .{ }^{*} P<0.05$ versus control (untreated), ${ }^{\#} P<0.05$ versus hemin.

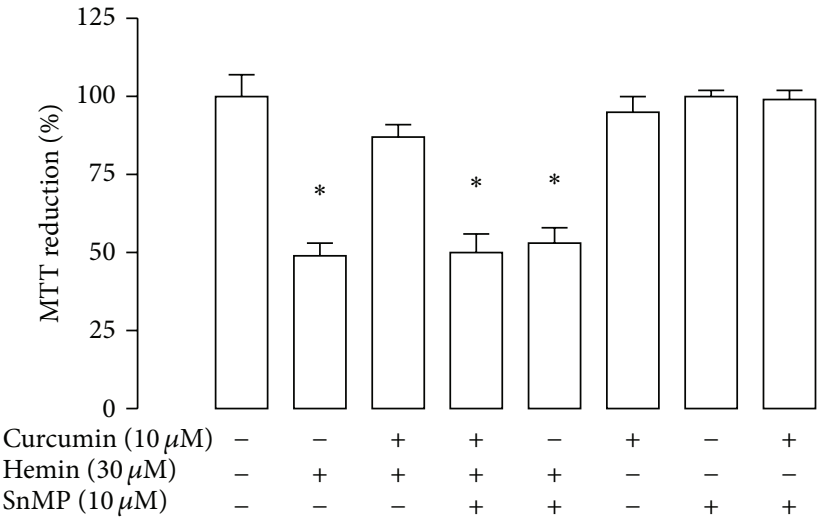

(a)

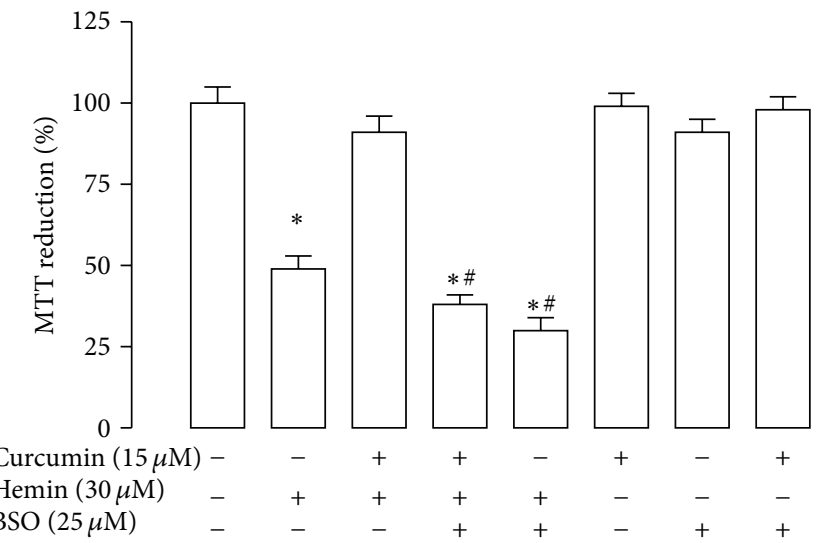

(b)

FIGURE 6: The protective effect of curcumin on hemin-induced cell death was prevented by the enzyme inhibitors tin mesoporphyrin (SnMP) or buthionine sulfoximine (BSO). CGNs were incubated with 10 and $15 \mu \mathrm{M}$ curcumin for $24 \mathrm{~h}$. The culture medium was removed and the inhibitors (a) SnMP or (b) BSO were added (15 min and $1 \mathrm{~h}$, resp.), before the addition of $30 \mu \mathrm{M}$ hemin. Subsequently these compounds were replaced by fresh medium and the incubation was continued in presence of inhibitors for $24 \mathrm{~h}$. Finally, cell viability was quantified by MTT reduction. Data are expressed as mean $\pm \mathrm{SEM}, n=6 .{ }^{*} P<0.05$ versus control (untreated), ${ }^{\#} P<0.05$ versus hemin. 

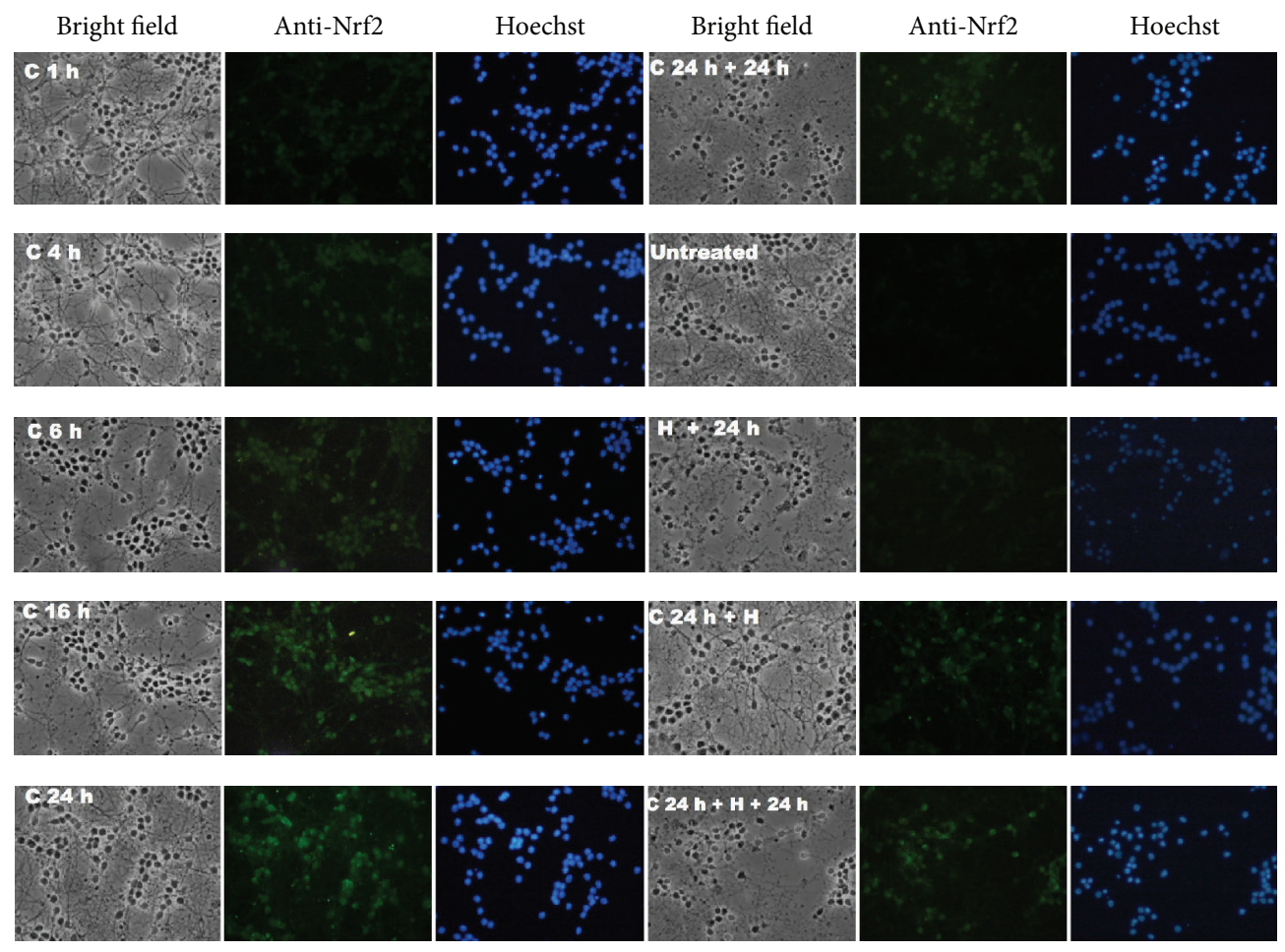

(a)

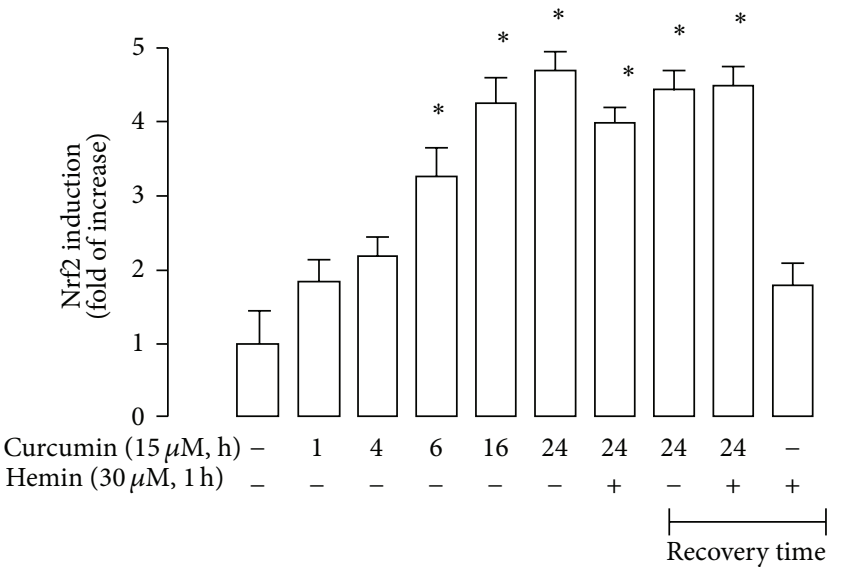

(b)

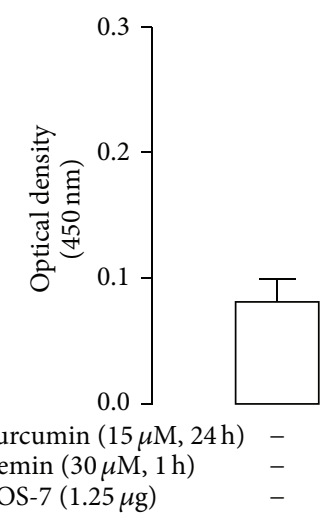

(c)

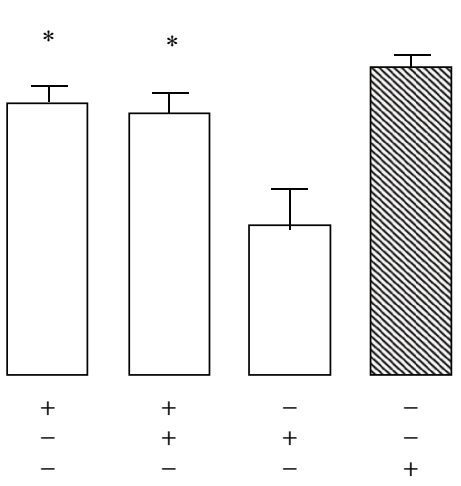

FIGURE 7: Immunocytochemistry localization and functional assay (antioxidant response element (ARE) binding) of Nrf2 in CGNs exposed to curcumin, curcumin/hemin, and hemin. Curcumin (C) was capable of inducing nuclear translocation and binding of nuclear Nrf2 to ARE before and after hemin (H)-exposure. (a) Representative images with bright-field (40x, left panel), anti-Nrf2 signal (middle panel) and Hoechst stain (right panel). The same field is shown in each condition. CGNs were incubated (1-24h) with $15 \mu \mathrm{M}$ curcumin (C $1 \mathrm{~h}, \mathrm{C} 4 \mathrm{~h}, \mathrm{C}$ $6 \mathrm{~h}, \mathrm{C} 16 \mathrm{~h}, \mathrm{C} 24 \mathrm{~h})$. In addition, cells were pretreated for $24 \mathrm{~h}$ with curcumin and then exposed to $30 \mu \mathrm{M}$ hemin for $1 \mathrm{~h}(\mathrm{C} 24 \mathrm{~h}+\mathrm{H})$. Additional conditions were the following: CGNs were incubated by $24 \mathrm{~h}$ with $15 \mu \mathrm{M}$ curcumin and $24 \mathrm{~h}$ of recovery was allowed (C $24 \mathrm{~h}+24 \mathrm{~h}$ ), CGNs were incubated by $24 \mathrm{~h}$ with $15 \mu \mathrm{M}$ curcumin, then curcumin was removed, and $30 \mu \mathrm{M}$ hemin was added by $1 \mathrm{~h}$ and removed and $24 \mathrm{~h}$ of recovery was allowed (C $24 \mathrm{~h}+\mathrm{H}+24 \mathrm{~h}$ ) and CGNs were incubated by $30 \mu \mathrm{M}$ hemin by $1 \mathrm{~h}$ and then removed and $24 \mathrm{~h}$ of recovery was allowed $(\mathrm{H}+24 \mathrm{~h}$ ). (b) Intensity of fluorescence was measured in five different fields per well per condition. (c) Curcumin was incubated for $24 \mathrm{~h}$ or hemin for $1 \mathrm{~h}$ and the transcriptional activity of $\mathrm{Nrf} 2$ was measured at $450 \mathrm{~nm}$ using immobilized oligonucleotides containing the ARE consensus binding site. COS-7 nuclear extract was used as a positive control of this assay. Data are expressed as mean \pm SEM, $n=3$. ${ }^{*} P<0.05$ versus control (untreated) and versus hemin. 


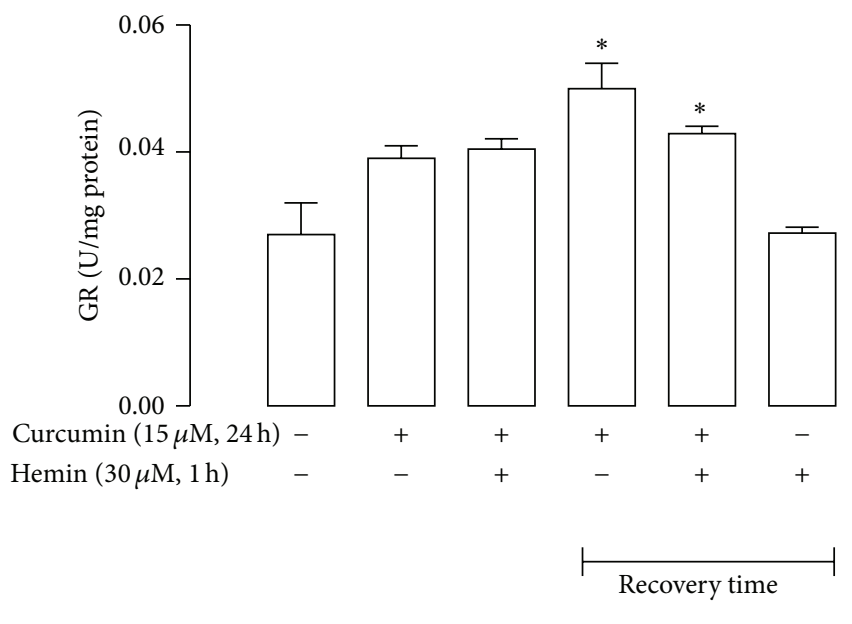

(a)

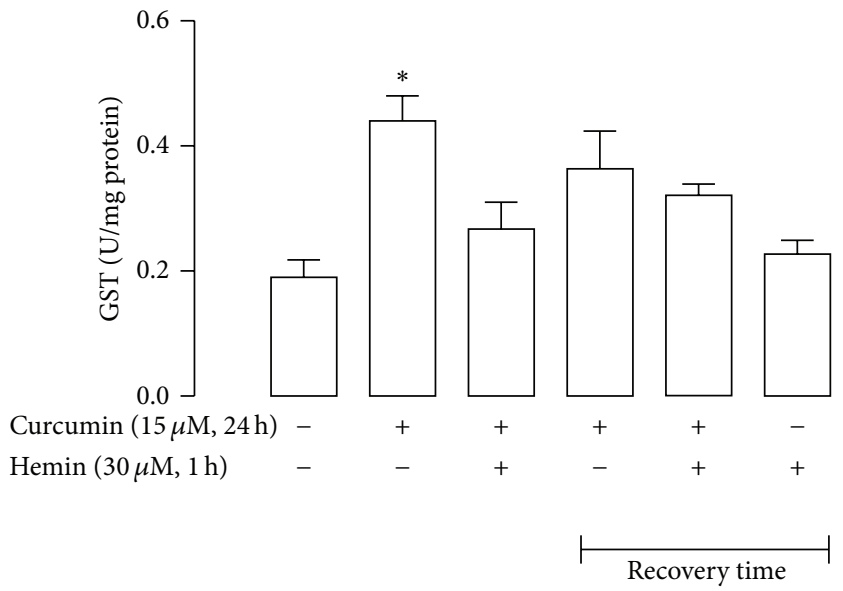

(b)

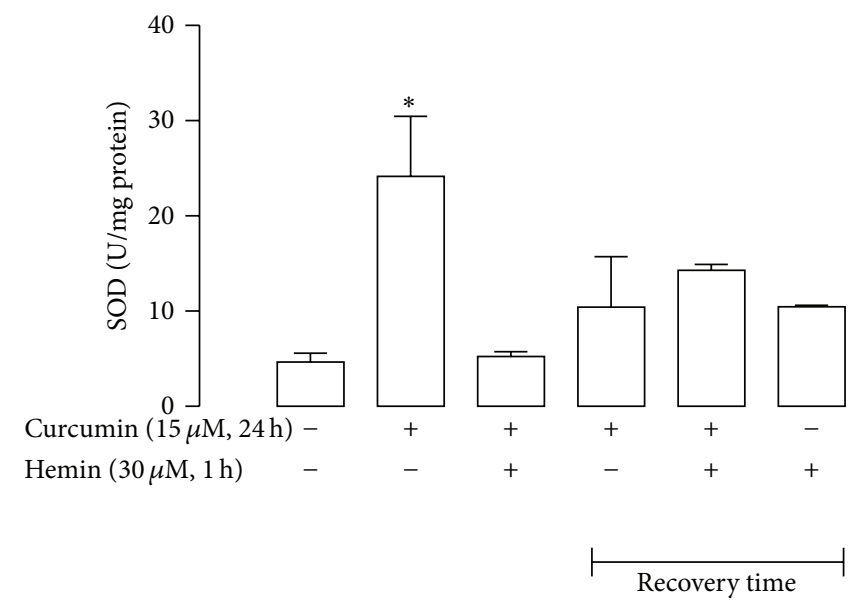

(c)

FIGURE 8: Curcumin increased activity of antioxidant enzymes in CGNs. (a) Glutathione reductase (GR), (b) glutathione-S-transferase (GST) and (c) superoxide dismutase (SOD). CGNs were treated with $15 \mu \mathrm{M}$ curcumin for $24 \mathrm{~h}$. The culture medium was removed and then $30 \mu \mathrm{M}$ hemin was added for $1 \mathrm{~h}$. Hemin was subsequently replaced by fresh medium and the incubation was continued. Recovery time $24 \mathrm{~h}$ after exposition to hemin or curcumin was considered (see legend to Figure 7). Data are expressed as mean \pm SEM, $n=3-5$. ${ }^{*} P<0.05$ versus control (untreated).

cellular damage was shown after $1 \mathrm{~h}$ of incubation with hemin. HO-1 expression was not significantly increased with hemin at the time and concentrations used in this work (data not shown). On the other hand, it has been known that curcumin can provide neuroprotection via ROS scavenging, iron chelation, modulation of cell-signaling pathways, and inhibition of inflammation [38, 40]. Moreover, curcumin is able to cross the blood-brain barrier and is neuroprotective in neurological disorders. Several studies in different experimental models of Parkinson's and Alzheimer's diseases strongly support the clinical application of curcumin in these pathologies [41, 42].

Based on the above data, it was found that curcumin was not toxic to CGNs in concentrations below $50 \mu \mathrm{M}$ when incubated for $24 \mathrm{~h}$. Also, only pretreatment of curcumin prevented hemin-induced cell death, and the cotreatment with curcumin/hemin failed to protect neurons. It was found that curcumin was effective to prevent oxidative damage in cultured neurons only when it was added as a pretreatment. Interestingly, this has been observed in rats with potassium dichromate-induced nephrotoxicity [28] but not in rats with $5 / 6$ nephrectomy in which the curcumin posttreatment was effective to reverse renal damage [5]. This may suggest that posttreatment is effective only in some experimental in vivo studies.

Additionally, curcumin alone was able to slightly raise ROS production after $24 \mathrm{~h}$ of incubation, but this polyphenol was capable of blocking hemin-induced ROS formation. In this context, curcumin has been considered as a hormetin, because it is an inductor of mild stress-induced of pathways of protection, maintenance, and repair $[26,27,43]$.

Curcumin may exert protective effects acting either as direct antioxidant or indirect antioxidant. ROS scavenging capacity of curcumin (direct antioxidant effect) is mainly attributed to its structure as a bis- $\alpha, \beta$-unsaturated $\beta$-diketone of two ferulic acid units, connected through a methylene 
group, and in addition, curcumin can modify the thiol groups of Keap1 releasing Nrf2 that migrates to the nucleus and induces the expression of antioxidant enzymes (indirect antioxidant effect) [1].

In the present study, curcumin induced HO-1 in CGNs in a concentration and time-dependent manner. In fact, it has been described that curcumin can raise HO-1 levels in different organs and models as in renal epithelial cells, rat hippocampal neurons, astrocytes, and normal human skin fibroblast $[18,27,44,45]$. It was found that the protective effect of curcumin was blocked with SnMP suggesting a role of $\mathrm{HO}$ in the protective function, in CGNs. There are evidences that the products of $\mathrm{HO}$ reaction biliverdin (quickly converted into bilirubin by biliverdin reductase) and $\mathrm{CO}$ could give protection in cerebral vessels and CGNs $[29,31,46]$. However, SnMP was unable to exacerbate hemininduced cell death. These findings suggest that curcumin induces the expression of $\mathrm{HO}-1$ that is a part of the complete antioxidant response of the cells, which is involved in the cytoprotection.

The brain maintains a redox balance in oxidative conditions by increasing GSH levels that attenuates cell damage or death. GSH is synthesized by neurons and glial cells and is the most abundant soluble antioxidant molecule in the brain [47, 48]. In addition, GSH protects significantly neurons in vitro from oxidative condition induced by 6 -hydroxydopamine, Nmethyl-4-phenylpyridinium ion and dopamine $[49,50]$.

Curcumin increased significantly GSH levels in CGNs. Furthermore, hemin increased GSSG levels that were prevented by curcumin pre-treatment. Hemin can interact with GHS and thus prevents association of hemin with red cell membrane [51]. In addition, BSO was able to avoid protection on cell viability in cotreatment with curcumin and hemin. These results agree with those found in astrocytes treated with hemin suggesting a critical role for astroglial GSH in the cellular defense against oxidative stress in the brain. However, the mechanism whereby GSH limits hemin toxicity remains incompletely understood [22].

Taken these results together, we tested whether Nrf2 pathway was involved in this process, because the induction by curcumin of HO-1 and GSH synthesis and many detoxifying and cytoprotective enzymes is mediated by $\mathrm{Nrf} 2[1,45]$. Under no stress condition, Nrf2 controls basal expression of its target genes and is continually targeted by Keap1 for degradation catalyzed by the $26 \mathrm{~S}$ proteasome via the ubiquitin-dependent way [52].

It has been shown that curcumin induces $\mathrm{Nrf} 2$ in a variety of models [4, 5, 27, 45, 53, 54]. Curcumin is an effective activator of the Keap1-Nrf2 pathway because it is a double Michael acceptor that contains two acceptor groups and is able to form conjugates with two thiol groups [14]. It was found that curcumin activates and translocates to nuclear localization of Nrf2 in CGNs. Nrf2 was readily detectable after $4 \mathrm{~h}$ and persisted over a period of at least $24 \mathrm{~h}$ of exposure, with apparent maximal amounts of Nrf2 observed after $16 \mathrm{~h}$ of exposure. In regard to time, curcumin showed maximal activation of Nrf2 from 8 to $48 \mathrm{~h}$ in diverse models $[27,37,54]$. Also with the flavonoid quercetin, nuclear location of $\mathrm{Nrf} 2$ was seen with $24 \mathrm{~h}$ of incubation in CGNs [55]. This suggests that over the time metabolism of phytochemical compounds is significant in generating mild stress which activates Nrf2.

In addition, we also evaluated the effect of curcumin in CGNs on enzyme activity of GR, GST, and SOD that are cytoprotective enzymes regulated by the Nrf2 pathway. Our results demonstrate that curcumin was able to increase the activity of these enzymes and pretreatment before the addition of hemin was capable of augmenting it. In neurons, the amount of GR is enough to allow the quick reduction of the accumulated GSSG. Under oxidative stress, GR maintains the equilibrium of the $[\mathrm{GSH}] /[\mathrm{GSSG}]$ redox state in the cell [56]. Several xenobiotics react with GST to form GSH conjugation, leading to detoxication of these compounds and their excretion from the cell [47]. SOD catalyzes the dismutation of superoxide radicals into $\mathrm{H}_{2} \mathrm{O}_{2}$ which is then converted into water by catalase, glutathione peroxidase, or peroxiredoxin [21]. This is related with hemorrhagic stroke, because injury is reduced in mice overexpressing SOD, including diminished expression of inducible nitric oxide synthase within the cerebral cortex and attenuation of peroxidative damage $[57,58]$.

\section{Conclusions}

Our data suggest that the pretreatment with curcumin induces $\mathrm{Nrf} 2$ and an antioxidant response that may be involved in the protective effect of this antioxidant against hemin-induced neuronal death.

\section{Conflict of Interests}

The authors declare no conflict of interests.

\section{Acknowledgments}

This works was supported in part by CONACYT 1298938 and PAPIIT IN210713. The authors thank Dr. Ismael Torres, Dr. Enrique Pinzon, and MVZ Atonatiuh Gómez for continuous technical support with the experimental animals.

\section{References}

[1] T. Esatbeyoglu, P. Huebbe, I. M. Ernst et al., "Curcumin—from molecule to biological function," Angewandte Chemie-International Edition, vol. 51, no. 22, pp. 5308-5332.

[2] F. Correa, M. Buelna-Chontal, S. Hernandez-Resendiz et al., "Curcumin maintains cardiac and mitochondrial function in chronic kidney disease," Free Radical Biology and Medicine C, vol. 61, pp. 119-129, 2013.

[3] A. González-Salazar, E. Molina-Jijón, F. Correa et al., "Curcumin protects from cardiac reperfusion damage by attenuation of oxidant stress and mitochondrial dysfunction," Cardiovascular Toxicology, vol. 11, no. 4, pp. 357-364, 2011.

[4] E. Tapia, V. Soto, K. M. Ortiz-Vega et al., "Curcumin induces Nrf2 nuclear translocation and prevents glomerular hypertension, hyperfiltration, oxidant stress, and the decrease in antioxidant enzymes in 5/6 nephrectomized rats," Oxidative Medicine and Cellular Longevity, vol. 2012, Article ID 269039, 14 pages, 2012. 
[5] E. Tapia, Z. L. Zatarain-Barron, R. Hernandez-Pando et al., "Curcumin reverses glomerular hemodynamic alterations and oxidant stress in 5/6 nephrectomized rats," Phytomedicine, vol. 20, no. 3-4, pp. 359-366, 2013.

[6] J. Epstein, I. R. Sanderson, and T. T. MacDonald, "Curcumin as a therapeutic agent: the evidence from in vitro, animal and human studies," British Journal of Nutrition, vol. 103, no. 11, pp. 1545-1557, 2010.

[7] B. Sung, S. Prasad, V. R. Yadav et al., "Cancer cell signaling pathways targeted by spice-derived nutraceuticals," Nutrition and Cancer, vol. 64, no. 2, pp. 173-197, 2012.

[8] J. Trujillo, Y. I. Chirino, E. Molina-Jijon et al., "Renoprotective effect of the antioxidant curcumin: recent findings," Redox Biology, vol. 1, no. 1, p. 9, 2013.

[9] A. Barzegar and A. A. Moosavi-Movahedi, "Intracellular ROS protection efficiency and free radical-scavenging activity of curcumin," PLoS ONE, vol. 6, no. 10, Article ID e26012, 2011.

[10] A. T. Dinkova-Kostova and P. Talalay, "Direct and indirect antioxidant properties of inducers of cytoprotective proteins," Molecular Nutrition and Food Research, vol. 52, supplement 1, pp. S128-S138, 2008.

[11] L. M. Reyes-Fermin, S. Gonzalez-Reyes, N. G. Tarco-Alvarez et al., "Neuroprotective effect of alpha-mangostin and curcumin against iodoacetate-induced cell death," Nutritional Neuroscience, vol. 15, no. 5, pp. 34-41, 2012.

[12] R. Pinkus, L. M. Weiner, and V. Daniel, "Role of oxidants and antioxidants in the induction of AP- $1, \mathrm{NF}-\kappa \mathrm{B}$, and glutathione S-transferase gene expression," Journal of Biological Chemistry, vol. 271, no. 23, pp. 13422-13429, 1996.

[13] A. C. Anderica-Romero, I. G. Gonzalez-Herrera, A. Santamaria et al., "Cullin 3 as a novel target in diverse pathologies," Redox Biology, vol. 1, no. 1, pp. 366-372, 2013.

[14] K. T. Turpaev, "Keap1-Nrf2 signaling pathway: mechanisms of regulation and role in protection of cells against toxicity caused by xenobiotics and electrophiles," Biochemistry, vol. 78, no. 2, pp. 111-126, 2013.

[15] H. K. Bryan, A. Olayanju, C. E. Goldring et al., "The Nrf2 cell defence pathway: Keap1-dependent and-independent mechanisms of regulation," Biochemical Pharmacology, vol. 85, no. 6, pp. 705-717, 2013.

[16] S. C. Gupta, S. Prasad, J. H. Kim et al., "Multitargeting by curcumin as revealed by molecular interaction studies," Natural Product Reports, vol. 28, no. 12, pp. 1937-1955, 2011.

[17] A. A. Canales-Aguirre, U. A. Gomez-Pinedo, S. Luquin, M. A. Ramírez-Herrera, M. L. Mendoza-Magaña, and A. FeriaVelasco, "Curcumin protects against the oxidative damage induced by the pesticide parathion in the hippocampus of the rat brain," Nutritional Neuroscience, vol. 15, no. 2, pp. 62-69, 2012.

[18] G. Scapagnini, C. Colombrita, M. Amadio et al., "Curcumin activates defensive genes and protects neurons against oxidative stress," Antioxidants and Redox Signaling, vol. 8, no. 3-4, pp. 395-403, 2006.

[19] R. F. Regan, Y. Wang, X. Ma, A. Chong, and Y. Guo, "Activation of extracellular signal-regulated kinases potentiates hemin toxicity in astrocyte cultures," Journal of Neurochemistry, vol. 79, no. 3, pp. 545-555, 2001.

[20] S. R. Robinson, T. N. Dang, R. Dringen, and G. M. Bishop, "Hemin toxicity: a preventable source of brain damage following hemorrhagic stroke," Redox Report, vol. 14, no. 6, pp. 228235, 2009.
[21] B. Harwell, "Biochemistry of oxidative stress," Biochemical Society Transactions, vol. 35, part 5, pp. 1147-1150, 2007.

[22] M. D. Laird, C. Wakade, C. H. Alleyne Jr., and K. M. Dhandapani, "Hemin-induced necroptosis involves glutathione depletion in mouse astrocytes," Free Radical Biology and Medicine, vol. 45, no. 8, pp. 1103-1114, 2008.

[23] T. N. Dang, G. M. Bishop, R. Dringen, and S. R. Robinson, "The metabolism and toxicity of hemin in astrocytes," Glia, vol. 59, no. 10, pp. 1540-1550, 2011.

[24] T. N. Dang, S. R. Robinson, R. Dringen, and G. M. Bishop, "Uptake, metabolism and toxicity of hemin in cultured neurons," Neurochemistry International, vol. 58, no. 7, pp. 804-811, 2011.

[25] M. C. Dai, Z. H. Zhong, Y. H. Sun et al., "Curcumin protects against iron induced neurotoxicity in primary cortical neurons by attenuating necroptosis," Neuroscience Letters, vol. 536, pp. 41-46, 2013.

[26] D. Demirovic and S. I. S. Rattan, "Curcumin induces stress response and hormetically modulates wound healing ability of human skin fibroblasts undergoing ageing in vitro," Biogerontology, vol. 12, no. 5, pp. 437-444, 2011.

[27] C. F. Lima, C. Pereira-Wilson, and S. I. S. Rattan, "Curcumin induces heme oxygenase-1 in normal human skin fibroblasts through redox signaling: relevance for anti-aging intervention," Molecular Nutrition and Food Research, vol. 55, no. 3, pp. 430442, 2011.

[28] E. Molina-Jijón, E. Tapia, C. Zazueta et al., "Curcumin prevents $\mathrm{Cr}(\mathrm{VI})$-induced renal oxidant damage by a mitochondrial pathway," Free Radical Biology and Medicine, vol. 51, no. 8, pp. 1543-1557, 2011.

[29] S. González-Reyes, M. Orozco-Ibarra, S. Guzmán-Beltrán, E. Molina-Jijón, L. Massieu, and J. Pedraza-Chaverri, "Neuroprotective role of heme-oxygenase 1 againts iodoacetate-induced toxicity in rat cerebellar granule neurons: role of bilirubin," Free Radical Research, vol. 43, no. 3, pp. 214-223, 2009.

[30] S. Guzmán-Beltrán, S. Espada, M. Orozco-Ibarra, J. PedrazaChaverri, and A. Cuadrado, "Nordihydroguaiaretic acid activates the antioxidant pathway $\mathrm{Nrf} 2 / \mathrm{HO}-1$ and protects cerebellar granule neurons against oxidative stress," Neuroscience Letters, vol. 447, no. 2-3, pp. 167-171, 2008.

[31] M. Orozco-Ibarra, A. M. Estrada-Sánchez, L. Massieu, and J. Pedraza-Chaverrí, "Heme oxygenase-1 induction prevents neuronal damage triggered during mitochondrial inhibition: role of CO and bilirubin," International Journal of Biochemistry and Cell Biology, vol. 41, no. 6, pp. 1304-1314, 2009.

[32] J. Pedraza-Chaverrí, L. M. Reyes-Fermín, E. G. Nolasco-Amaya et al., "ROS scavenging capacity and neuroprotective effect of $\alpha$-mangostin against 3-nitropropionic acid in cerebellar granule neurons," Experimental and Toxicologic Pathology, vol. 61, no. 5, pp. 491-501, 2009.

[33] V. P. Bindokas and A. T. Ishida, "Conotoxin-sensitive and conotoxin-resistant $\mathrm{Ca} 2+$ currents in fish retinal ganglion cells," Journal of Neurobiology, vol. 29, no. 4, pp. 429-444, 1996.

[34] I. Rahman, A. Kode, and S. K. Biswas, "Assay for quantitative determination of glutathione and glutathione disulfide levels using enzymatic recycling method," Nature Protocols, vol. 1, no. 6, pp. 3159-3165, 2007.

[35] J. C. Fernandez-Checa and N. Kaplowitz, "The use of monochlorobimane to determine hepatic GSH levels and synthesis," Analytical Biochemistry, vol. 190, no. 2, pp. 212-219, 1990. 
[36] C. E. Guerrero-Beltran, M. Calderon-Oliver, E. Tapia et al., "Sulforaphane protects against cisplatin-induced nephrotoxicity," Toxicology Letters, vol. 192, no. 3, pp. 278-285, 2010.

[37] H. Jiang, X. Tian, Y. Guo, W. Duan, H. Bu, and C. Li, "Activation of nuclear factor erythroid 2-related factor 2 cytoprotective signaling by curcumin protect primary spinal cord astrocytes against oxidative toxicity," Biological and Pharmaceutical Bulletin, vol. 34, no. 8, pp. 1194-1197, 2011.

[38] M. N. A. Mandal, J. M. R. Patlolla, L. Zheng et al., "Curcumin protects retinal cells from light-and oxidant stress-induced cell death," Free Radical Biology and Medicine, vol. 46, no. 5, pp. 672679, 2009.

[39] A. Yadav, V. Lomash, M. Samim et al., "Curcumin encapsulated in chitosan nanoparticles: a novel strategy for the treatment of arsenic toxicity," Chemico-Biological Interactions, vol. 199, no. 1, pp. 49-61, 2012.

[40] N. Kelsey, W. Hulick, A. Winter, E. Ross, and D. Linseman, "Neuroprotective effects of anthocyanins on apoptosis induced by mitochondrial oxidative stress," Nutritional Neuroscience, vol. 14, no. 6, pp. 249-259, 2011.

[41] R. B. Mythri and M. M. Srinivas Bharath, "Curcumin: a potential neuroprotective agent in Parkinson's disease," Current Pharmaceutical Design, vol. 18, no. 1, pp. 91-99, 2012.

[42] D. Yanagisawa, T. Amatsubo, S. Morikawa et al., "In vivo detection of amyloid $\beta$ deposition using19F magnetic resonance imaging with a19F-containing curcumin derivative in a mouse model of Alzheimer's disease," Neuroscience, vol. 184, pp. 120127, 2011.

[43] M. P. Mattson, "Hormesis defined," Ageing Research Reviews, vol. 7, no. 1, pp. 1-7, 2008.

[44] R. F. Regan, J. Chen, and L. Benvenisti-Zarom, "Heme oxygenase- 2 gene deletion attenuates oxidative stress in neurons exposed to extracellular hemin," BMC Neuroscience, vol. 5, article 34, 2004.

[45] E. Balogun, M. Hoque, P. Gong et al., "Curcumin activates the haem oxygenase-1 gene via regulation of $\mathrm{Nrf} 2$ and the antioxidant-responsive element," Biochemical Journal, vol. 371, part 3, pp. 887-895, 2003.

[46] H. Parfenova, C. W. Leffler, S. Basuroy, J. Liu, and A. L. Fedinec, "Antioxidant roles of heme oxygenase, carbon monoxide, and bilirubin in cerebral circulation during seizures," Journal of Cerebral Blood Flow and Metabolism, vol. 32, no. 6, pp. 1024$1034,2012$.

[47] K. Aoyama, M. Watabe, and T. Nakaki, "Regulation of neuronal glutathione synthesis," Journal of Pharmacological Sciences, vol. 108, no. 3, pp. 227-238, 2008.

[48] C. Mytilineou, B. C. Kramer, and J. A. Yabut, "Glutathione depletion and oxidative stress," Parkinsonism and Related Disorders, vol. 8, no. 6, pp. 385-387, 2002.

[49] M. B. Spina, S. P. Squinto, J. Miller, R. M. Lindsay, and C. Hyman, "Brain-derived neurotrophic factor protects dopamine neurons against 6- hydroxydopamine and N-methyl-4-phenylpyridinium ion toxicity: involvement of the glutathione system," Journal of Neurochemistry, vol. 59, no. 1, pp. 99-106, 1992.

[50] A. H. Stokes, D. Y. Lewis, L. H. Lash et al., "Dopamine toxicity in neuroblastoma cells: role of glutathione depletion byL-BSO and apoptosis," Brain Research, vol. 858, no. 1, pp. 1-8, 2000.

[51] V. E. Sahini, M. Dumitrescu, E. Volanschi, L. Birla, and C. Diaconu, "Spectral and interferometrical study of the interaction of haemin with glutathione," Biophysical Chemistry, vol. 58, no. 3, pp. 245-253, 1996.
[52] T. Nguyen, P. Nioi, and C. B. Pickett, "The Nrf2-antioxidant response element signaling pathway and its activation by oxidative stress," Journal of Biological Chemistry, vol. 284, no. 20, pp. 13291-13295, 2009.

[53] I. Carmona-Ramirez, A. Santamaria, J. C. Tobon-Velasco et al., "Curcumin restores Nrf2 levels and prevents quinolinic acidinduced neurotoxicity," The Journal of Nutritional Biochemistry, vol. 24, no. 1, pp. 14-24, 2013.

[54] C. Yang, X. Zhang, H. Fan, and Y. Liu, "Curcumin upregulates transcription factor Nrf2, HO-1 expression and protects rat brains against focal ischemia," Brain Research, vol. 1282, pp. 133$141,2009$.

[55] F. Arredondo, C. Echeverry, J. A. Abin-Carriquiry et al., "After cellular internalization, quercetin causes Nrf2 nuclear translocation, increases glutathione levels, and prevents neuronal death against an oxidative insult," Free Radical Biology and Medicine, vol. 49, no. 5, pp. 738-747, 2010.

[56] R. Dringen, L. Kussmaul, J. M. Gutterer, J. Hirrlinger, and B. Hamprecht, "The glutathione system of peroxide detoxification is less efficient in neurons than in astroglial cells," Journal of Neurochemistry, vol. 72, no. 6, pp. 2523-2530, 1999.

[57] M. J. McGirt, A. Parra, H. Sheng et al., "Attenuation of cerebral vasospasm after subarachnoid hemorrhage in mice overexpressing extracellular superoxide dismutase," Stroke, vol. 33, no. 9, pp. 2317-2323, 2002.

[58] A. Saito, H. Kamii, I. Kato et al., "Transgenic CuZn-superoxide dismutase inhibits NO synthase induction in experimental subarachnoid hemorrhage," Stroke, vol. 32, no. 7, pp. 1652-1656, 2001. 


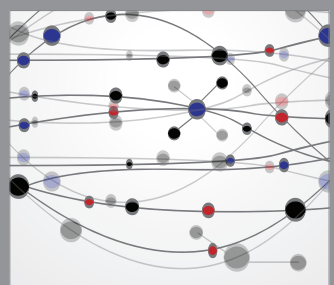

The Scientific World Journal
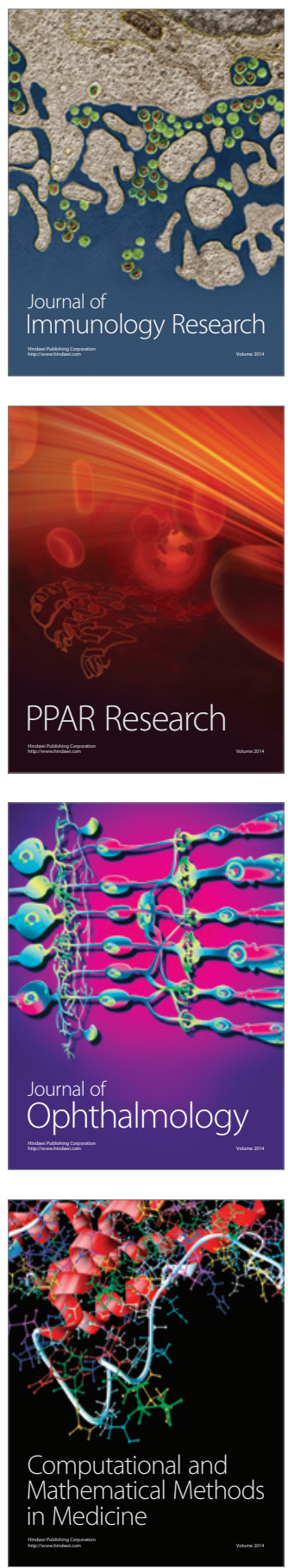

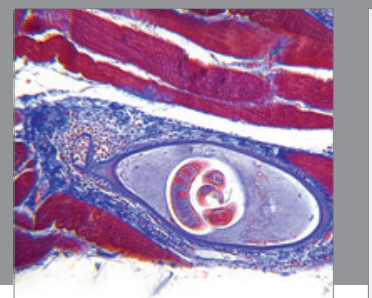

Gastroenterology

Research and Practice
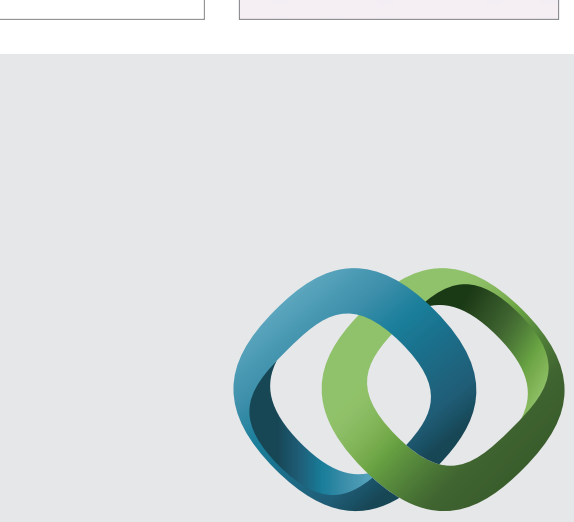

\section{Hindawi}

Submit your manuscripts at

http://www.hindawi.com
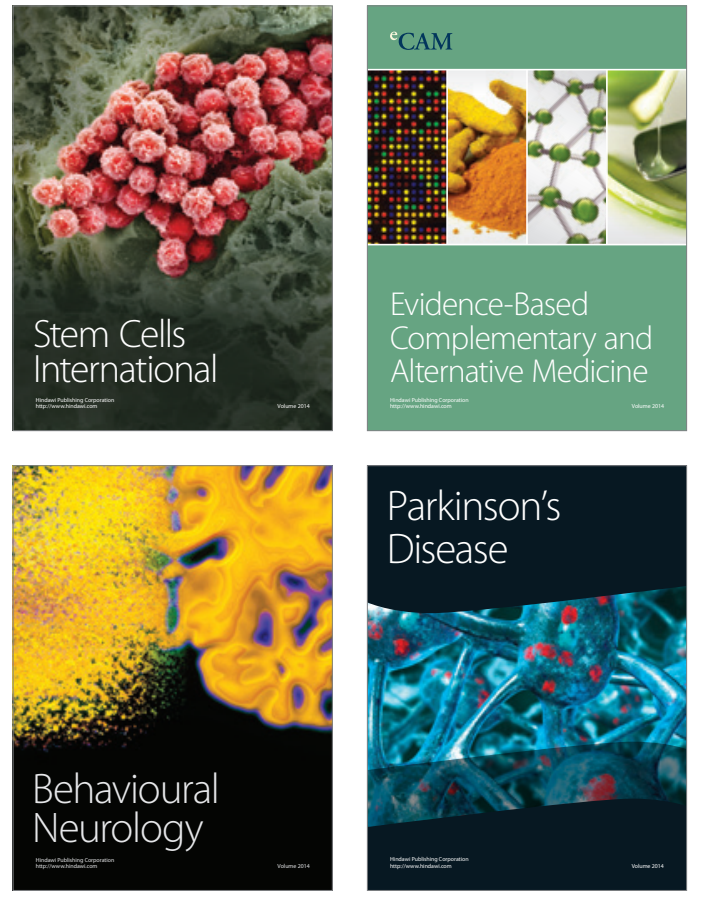
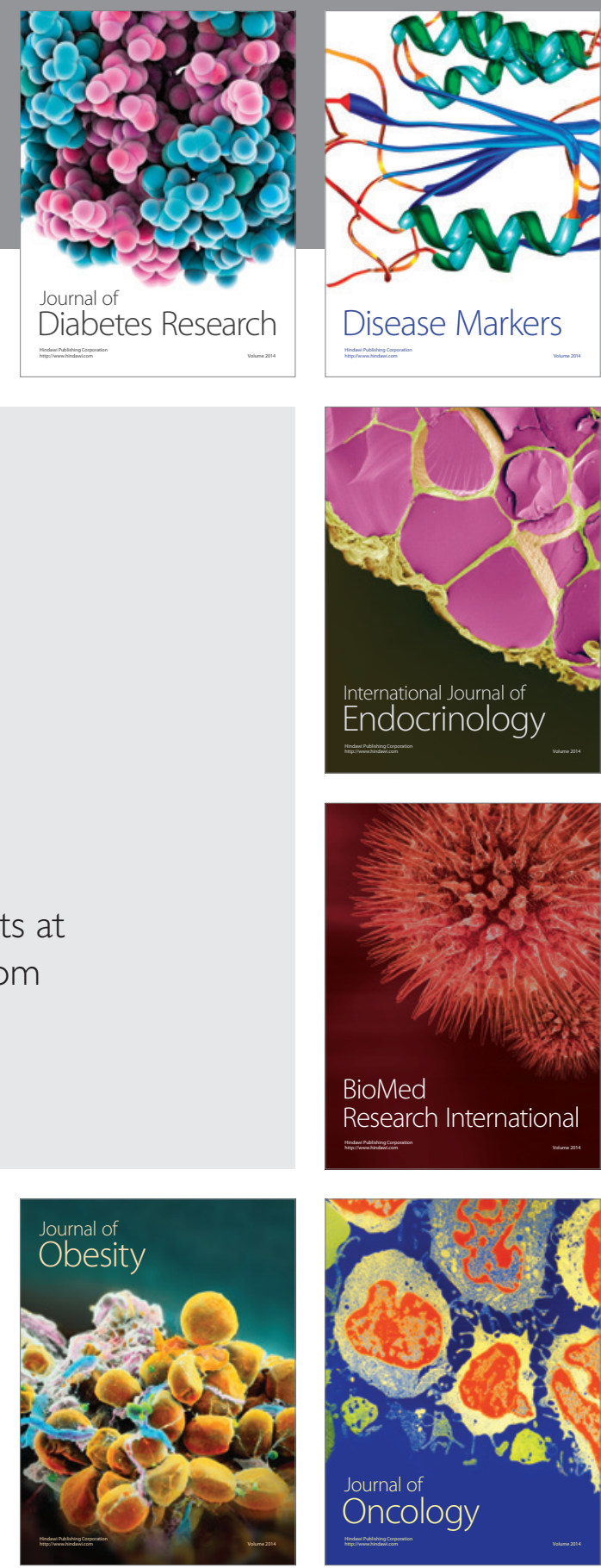

Disease Markers
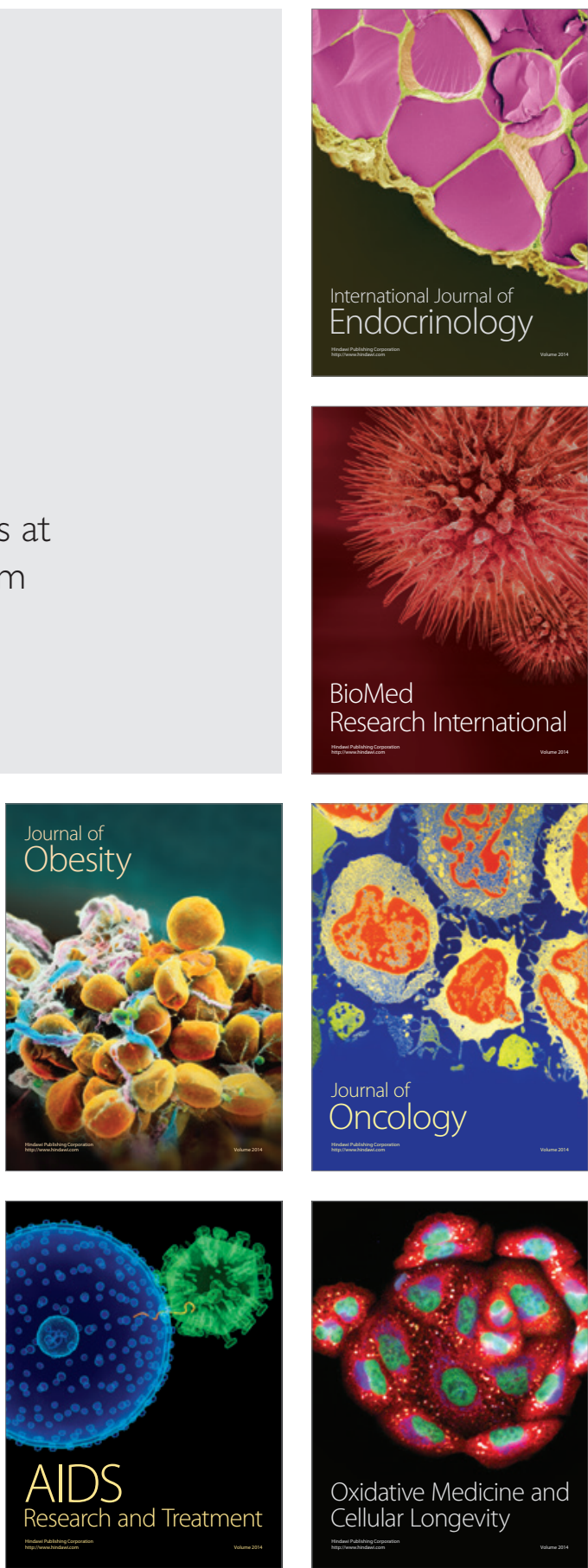